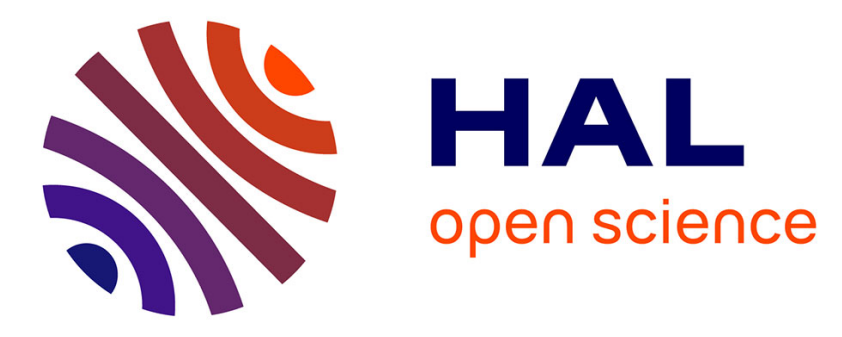

\title{
Potential limitations of IL-2 administration for the treatment of experimental acute graft-versus-host disease
}

Louis Pérol, Gaëlle H. Martin, Sébastien Maury, José L. Cohen, Eliane Piaggio

\section{- To cite this version:}

Louis Pérol, Gaëlle H. Martin, Sébastien Maury, José L. Cohen, Eliane Piaggio. Potential limitations of IL-2 administration for the treatment of experimental acute graft-versus-host disease. Immunology Letters, 2014, 162 (2B), pp.173-184. 10.1016/j.imlet.2014.10.027 . hal-01090548

\author{
HAL Id: hal-01090548 \\ https://hal.science/hal-01090548
}

Submitted on 3 Dec 2014

HAL is a multi-disciplinary open access archive for the deposit and dissemination of scientific research documents, whether they are published or not. The documents may come from teaching and research institutions in France or abroad, or from public or private research centers.
L'archive ouverte pluridisciplinaire HAL, est destinée au dépôt et à la diffusion de documents scientifiques de niveau recherche, publiés ou non, émanant des établissements d'enseignement et de recherche français ou étrangers, des laboratoires publics ou privés. 


\section{Potential limitations of IL-2 administration for the treatment of experimental acute graft-versus-host disease}

Louis Pérol ${ }^{1,2,3,4,5^{* \dagger}}$, Gaëlle H. Martin (PhD ${ }^{\star 6,7}$, Sébastien Maury ${ }^{6,7,8}$, José L. Cohen $(\mathrm{PhD})^{\star \star 6,7,8}$ and Eliane Piaggio $(\mathrm{PhD})^{\star \star 1,2,3,4,5,9 \dagger}$

1. INSERM U932, 26 rue d'Ulm, 75005 Paris, France;

2. Institut Curie, Section Recherche, 26 rue d'Ulm, 75005 Paris, France;

3. Université Pierre et Marie Curie Paris 06, UMR7211, ImmunologyImmunopathology-Immunotherapy (I3), F-75013 Paris, France.

4. INSERM, UMR_S959, I3, F-75013 Paris, France.

5. CNRS, UMR7211, I3, F-75013 Paris, France.

6. Université Paris-Est Créteil, Faculté de médecine, Créteil F-94010, France;

7. INSERM U 955, Institut Mondor de Recherche Biomédicale (IMRB), Créteil F94010, France;

8. AP-HP, Groupe Hospitalier Henri-Mondor Albert-Chenevier, CIC-BT-504, Créteil, France.

9. INSERM Center of Clinical Investigation (CIC-BT-507), 75005 Paris, France;

* equally contributed to this work

** equally contributed to this work and corresponding authors:

Correspondence should be addressed to: Eliane Piaggio, Institut Curie, Section Recherche, 26 rue d'Ulm, 75005 Paris, France, phone tel: + 33 1.56.24.58.05; fax: + 33 1.56.24.64.38 (eliane.piaggio@yahoo.com) or José L. Cohen, Institut Mondor 
de Recherche Biomédicale, Groupe hospitalier Henri-Mondor Albert-Chenevier, 51 avenue du Maréchal de Lattre de Tassigny, Créteil F-94010 France; phone +33149 8137 96, fax +33 149813797 (jose.cohen@inserm.fr).

† current address: ${ }^{4}$ INSERM U932, 26 rue d'UIm, 75005 Paris, France.

Sort title: Effect of IL-2 treatment on acute GVHD

Keywords: IL-2, bone marrow transplantation, graft-vs-host disease, regulatory $\mathrm{T}$ cell, immunotherapy. 


\section{ABSTRACT}

Low-dose IL-2 administration can control autoimmunity by specifically activating CD4+FoxP3+ regulatory T cells (Tregs). Here, we studied IL-2-based immunotherapy in experimental graft-versus-host disease (GVHD). IL-2 administration to donor mice induced a dose-dependent expansion of Tregs in the graft but was insufficient to control GVHD. IL-2 administration to allogeneic-grafted recipient mice activated Tconventional cells (Tcons) and did not prevent GVHD. This loss of IL-2 selectivity towards Tregs was explained by an IL-2-induced increase in the IL-2 receptor $\alpha$ chain expression on Tcons. Finally, in xeno-GVHD generated by human PBMCs transplanted into immunodeficient mice, low-dose IL-2 increased Treg frequencies but did neither control pro-inflammatory cytokine production by pathogenic Tcons, nor prevented GVHD. Furthermore, combination of low-dose IL-2 with rapamycin was ineffective in this model. Our results indicate that limitations on the use of IL-2 during acute GVHD are likely due to the massive activation of the allogeneic T cells unique to this setting.

Key words: BMT, Interleukin-2, GVHD, xeno-GVHD, regulatory $\mathrm{T}$ cell, immunotherapy. 


\subsection{INTRODUCTION}

Allogeneic hematopoietic stem cell transplantation (allo-HCT) is the treatment of choice for many hematological malignancies and primary immunodeficiencies. The efficacy of such therapy is compromised by the presence of allogeneic donor mature T cells within the graft, which are responsible for a life threatening complication: graftversus-host disease (GVHD) [1]. It is now assumed that thymus-derived regulatory T cells (Treg) could modulate allogeneic immune responses as demonstrated in different experimental models (for recent review see [2]). Initially, we and others have demonstrated that adding high numbers of regulatory $T$ cells (Tregs) to the graft could prevent GVHD [3-5]. In particular, Tregs that were rendered specific for recipient allo-antigens $[6,7]$ or exogenous nominal Ag through ex-vivo activation [8] prevented GVHD while retaining the ability of donor T cells to mediate graft-versustumor effects and promote immune reconstitution. However, despite the fact that the preparation of clinical grade Treg was strongly improved in the recent years, this remains a complex process, particularly for the generation of antigen specific Treg [9, 10]. Consequently, in vivo direct stimulation of Treg compartment could be a more accessible alternative for decreasing GVHD incidence.

Interleukin-2 (IL-2) was initially described for its capacity to stimulate T-cell proliferation in vitro $[11,12]$. Consequently, IL-2 at high doses has been used clinically to stimulate anti-tumor or anti-viral immune responses in patients with metastatic melanoma, metastatic renal carcinoma and HIV, respectively [13-17]. Although these results have demonstrated a pleïotropic effect of IL-2 on immune cells, recent advances have shown that the principal non-redundant role of IL-2 is the maintenance of Treg homeostasis [18]. Indeed, mice lacking functional IL-2 or IL-2 
receptors develop severe autoimmunity in association with abnormal homeostasis of Tregs $[19,20]$ establishing that IL-2 is essential for Treg development, proliferation and peripheral survival $[21,22]$. In this line, we recently demonstrated that treatment of young non-obese diabetic (NOD) mice with low-dose IL-2 prevents [23] and reverts [24] type 1 diabetes (T1D) development. In this setting, IL-2 can revert established autoimmunity by acting with exquisite selectivity, expanding and activating Tregs only in the inflamed pancreas while leaving pathogenic conventional T cells (Tcons) unaffected.

IL-2-based treatment was also envisaged for GVHD prophylaxis. During the 90's, pioneer work by the group of David Sachs [25-27] showed that 3 days of IL-2 administration could control experimental GVHD development. In contrast, Shin et al reported the lack of therapeutic effect of IL-2 on experimental GVHD [28]. In this last study, GVHD prophylaxis was only observed when IL-2 treatment was combined to rapamycin administration. It is thus to date difficult to conclude on the possibility to prevent GVHD by the sole IL-2 administration in experimental GVHD. In humans, a recent clinical trial aimed at evaluating the effect of ultra low dose (ULD) IL-2 for GVHD prophylaxis after allo-HCT. When IL-2 treatment was combined with a standard immunosuppressive regimen, an increased proportion of Treg was observed in approximately half of patients [29]. Additionally, Ito et al. [30] recently tested the possibility to increase the Treg content in twenty-one healthy volunteer donors by administrating ultra low dose (ULD) IL-2 treatment for 5 days. They observed that ULD IL-2 induced a significant increase in the frequency and the suppressive function of Treg that was maintained until day 7 . However, by showing that healthy donor could also be treated by IL-2 with minimal adverse events, the authors clearly pave the way for new clinical application for IL-2 therapy to prevent 
GVHD after HSCT. To directly address this issue, we tested for the first time the possibility to impact experimental GVHD by administrating low-dose IL-2 in donor mice over 5 days (as performed in the Ito's study) in order to selectively induce Treg expansion/activation. We also compared this approach with a second prophylactic strategy consisting in the direct administration of IL-2 to grafted mice in a model of acute allogeneic GVHD and in a model of xenogeneic (xeno-) GVHD consisting in the administration of human PBMCs to immunodeficient mice. 


\subsection{RESULTS}

\subsubsection{Low-dose IL-2-treatment of donor mice specifically increases Treg}

proportions

We reasoned that administration of low-dose IL-2 to immunocompetent donor mice could expand Tregs in the graft as recently showed by Ito et al. [30] in humans, and consequently prevent GVHD. Thus, we first studied the capacity of different doses of IL-2 administered over 5 days to selectively induce Treg expansion/activation in donor B6 mice (Figure 1a). Indeed, in this context of "healthy" donors (immunocompetent, unmanipulated mice), IL-2 treatment induced a dose-dependent increase in the proportion of Tregs in peripheral lymph nodes (Figure 1b-c). These expanded Tregs showed an activated phenotype, as attested by their IL-2-induced increased expression of CD25 and Foxp3 levels (Figure 1b-c). The distribution, of naïve and memory Tregs, Tconv and CD8+ T cells, as defined by the expression of CD44 and CD62L, was not significantly modified by the treatment (Figure 1d).

\subsubsection{Low-dose IL-2-treatment of donor mice does not prevent GVHD}

We then evaluated the capacity of $T$ cells collected from IL-2-treated donor mice to induce GVHD (Figure 2a). We observed that independently of the IL-2 pre-treatment, the transferred T cells induced similar GVHD, as attested by the similar pattern of body weight loss (Figure $\mathbf{2 b}$ ). Survival of the grafted mice was not ameliorated when grafts were obtained from IL-2 treated donors, and even tended to accelerate GVHDlinked mortality at the highest dose (Figure 2c). These results show that despite an IL-2-induced Treg enrichment in the graft, GVHD incidence in the recipient mice was not affected. 


\subsubsection{IL-2 administration to grafted mice does not affect GVHD incidence}

We previously demonstrated that Treg administration could reduce the activation and expansion of donor T cells in experimental allogeneic BM transplantation [3, 6]. We therefore investigated whether IL-2 administration to recipient mice, by boosting Tregs, could reduce acute GVHD. We used a parent into F1 strain combination, which mimics the uncommon and very aggressive clinical scenario of haplomismatch SCT because: (i) this combination enables evaluation of the sole donor versus host immune response since in fully allogeneic HSCT, the anti-donor immune response mediated by residual recipient immune cells could attenuate GVHD. (ii) Our aim was also to evaluate the impact of the inflammatory setting on the IL-2 effect. This model is the sole to allow GVHD in irradiated and non-irradiated recipient mice without modifying the genetic combination between donor and recipient mice. For this, recipient B6D2F1 mice were lethally irradiated and grafted with B6 bone marrow cells along with $\mathrm{B} 6 \mathrm{CD} 3+\mathrm{T}$ cells and treated daily with different IL-2 doses for 10 days (Figure 3a). We did not observe any protective effects against GVHD at any of the tested doses, nor were there any effects on survival or the body weight profile of grafted mice (Figure $\mathbf{3 b}$-c). Moreover, high IL-2 doses significantly accelerated death of the grafted mice compared to untreated mice $(p<0.05)$.

To rule out a direct toxic effect of IL-2, recipient mice were grafted only with BM cells and were treated with IL-2. In this setting, IL-2 was not lethally toxic but induced a mild delay in body weight gain only at the highest dose (Supplemental Figure 1), which could contribute to GVHD-related morbidity in semi-allogeneic BMT.

Finally, we evaluated the therapeutic capacity of delayed IL-2 administration. For this, we tested a curative IL-2 schedule beginning at day 10 or 15 after grafting, or alternatively, at detection of the first clinical signs of GVHD. As showed in 
Supplementary Figure 2, neither of these therapeutic approaches could control GVHD course.

\subsubsection{IL-2 administration to grafted mice does not affect $T$ cell reconstitution kinetics}

To follow the effect of IL-2 administration on the fate of donor T cells [31], we induced GVHD by infusing B6Luc+ LN T cells in lethally irradiated B6D2F1 recipient mice, treated or not with IL-2. As shown in Figure $\mathbf{4 a}$, the same kinetics of donor $\mathrm{T}$ cell expansion measured by bioluminescence detection was observed independent of IL2 treatment. Similarly, by flow cytometry analysis no significant differences were observed between PBS or IL-2-treated mice, neither in the frequency nor in the absolute number of Tregs or Tcons (Figure $\mathbf{4 b - d}$ ), confirming that IL-2 treatment did not affect the kinetics of early $\mathrm{T}$ cell reconstitution.

\subsubsection{During acute GVHD, IL-2 looses it selectivity for Tregs}

We studied the effect of IL-2 treatment on the T cell activation status. As shown in Figure 5, IL-2 administration preferentially activated CD8+ T cells as attested by the IL-2-dose-dependent increase in the proportion of effector/memory CD8+ T cells (CD44high, CD62L-) at expenses of the naïve CD8+ T cells (CD44low, CD62L+) (Figure 5a-b). Also, at the higher IL-2 dose, an increase in the MFI of ICOS and GITR among the CD8+ Tcon population was observed (Figure 5c-d). For the CD4+ Tcons, high-dose IL-2 administration only induced a significant increase in the MFI of GITR (Figure 5d).

In experimental allogeneic BMT, we previously observed that donor T cells rapidly divide and transiently acquire CD25 expression after transfer into recipient mice [32]. 
Of note, this transient expression of the high affinity IL-2 receptor likely endows the activated T cells with the ability to respond to reduced doses of IL-2 [33-35]. We thus evaluated the kinetics of CD25 expression on the different donor $\mathrm{T}$ cell subpopulations after in vivo IL-2 administration (Figure 6). In untreated grafted mice, donor CD4+ and CD8+ T cells showed a pick of CD25 expression by 3 days postgraft, which diminished by day 6 . Notably, in the presence of exogenous IL-2, The percentage of both CD4+ and CD8+ CD25+ allogeneic Tcons increased in a dosedependent manner (Figure 6a-b), and maintained very high expression levels of CD25 throughout the treatment (Figure 6a and c). Importantly, in IL-2 treated mice, increased expression of CD25 represented not only a biomarker of response to IL-2, but also a biomarker of cell activation (Supplemental Figure 3). Indeed, the CD25+ fraction of CD4+ and CD8+ Tcons obtained from IL-2 treated mice was significantly enriched in effector memory cells (CD44high, CD62L-) and showed increased expression of ICOS and GITR, compared to the CD25- fraction (Supplemental Figure 3a-b). Collectively, these results demonstrate that IL-2 treatment of recipient mice increased and sustained CD25 expression on allogeneic Tcons, endowing them with the capacity to respond to reduced amounts of IL-2, and thus explaining the lost of low-dose IL-2 administration specificity for Tregs.

In the autoimmune setting, low-dose IL-2 administration halts the pathogenic immune response through targeted boosting of Tregs in inflamed tissue [23, 24]. However, it could be argued that in allo-HCT, the lymphopenia associated with a cytokine storm due to conditioning [1] could be responsible for the absence of therapeutic effect of IL-2 during GVHD. To address this question, we turned to a mouse model of acute GVHD that allowed for controlling lymphopenia and the cytokine storm. We used a non-irradiated mouse model of GVHD [36] (Supplementary Figure 4). In this setting, 
the infusion of large numbers of parental $\mathrm{T}$ cells in F1 recipients resulted in $64 \%$ mortality at day 65 after transplantation and IL-2 administration did not significantly modify the course of GVHD (Supplementary Figure 4). Overall, these data suggest that neither inflammation induced by the radiation of the recipient, nor this conditioning-associated lymphopenia are responsible for the lack of protective effect of IL-2 during acute GVHD.

\subsubsection{Low-dose IL-2 expands human Tregs in PBMC administered in immunodeficient mice}

Low-dose IL-2 administration was recently described to reproducibly increase human Treg proportions in different immune-related pathologies, such as hepatitis $\mathrm{C}$ virusinduced vasculitis[37], autoimmune diabetes[38] and the allogeneic setting of patients suffering from chronic GVHD[39] or for GVHD prophylaxis in children[40]. We first wanted to test whether IL-2 administration could also increase Treg proportion in our experimental model of xenogeneic (xeno-) GVHD consisting in the administration of human PBMCs to immunodeficient mice. Thus, we administered 25,000 and 250,000 IU IL-2 (low- and high-IL-2 doses) and measured whether a similar effect on human Tregs was observed with PBMCs cells adoptively transferred into immunodeficient mice. At day 5, both IL-2 doses significantly increased Treg frequencies and proliferation (Figure 7a). At day 10, Treg proportions were increased in all conditions compared to day 5, but only low doses of IL-2 significantly increased Treg proportions compared with untreated mice $(P=0.04)$.

Next, we studied the specificity of IL-2 for Tregs as compared to the effect on Tconvs. Low-dose IL-2 treatment did not measurably affect CD4 or CD8 Tconv activation and proliferation as estimated by CD25 and Ki67 expression (Figure 7b). In marked 
contrast, although high-dose IL-2 administration increased Treg proportions, it also amplified the percentage of CD25 expressing CD4 Tconvs at day 10, as well as the percentage of Ki67 expressing CD4 and CD8 Tconvs at days 5 and 10. Thus, low dose IL-2 selectively expands Treg in vivo after adoptive transfer of PBMCs in immunodeficient mice.

\subsubsection{Treg expansion by low-dose IL-2 does not inhibit in vivo Tconv activation and differentiation during xeno-GVHD}

We next aimed to evaluate in vivo the biological effects of Treg expansion on human Tconv activation and differentiation in the context of GVHD. For this, we examined TNF $\square$ and IFN $\square$ production by Tconvs in the spleen and liver (a target organ of xeno-GVHD), as both cytokines represent pro-inflammatory mediators of acute GVHD[41, 42]. While low-dose IL-2 administration did not modify Tconv cytokine production compared to untreated mice, high-dose IL-2 dramatically increased the percentage of TNF $\square$ and INF $\square$ producing CD4 and CD8 Tconvs (Figure 7c). Overall, using human cells, we observed for the first time that high-doses of IL-2 increased pathogenic Tconv activation, proliferation and cytokine production, whereas low-dose IL-2 increased only Tregs proportions, which nevertheless were insufficient to control the production of inflammatory cytokines by the activated Tconvs.

\subsubsection{Low-dose IL-2 alone or combined to rapamycin does not prevent xeno- GVHD}

We then tested the clinical impact of Treg expansion on GVHD following several therapeutic schemes described in Figure 8a. As previously shown[43, 44], adoptive 
transfer of human PBMCs induced lethal xeno-GVHD (median survival time, MST = 42.5 days). Administration of low-doses of IL-2 did not significantly modify the disease course $(\mathrm{MST}=37.5$ days; $P=0.0626$ versus PBS-treated mice). Addition of rapamycin to low-dose IL-2 therapy did not ameliorate GVHD (Figure 8b). 


\subsection{DISCUSSION}

The few published studies of IL-2 administration during BMT are controversial. In this work, we observed that a wide range of low-dose IL-2 injections administered to grafted mice were inefficient for controlling GVHD. More precisely, 25,000 IU IL-2, which was the "low-dose IL-2" used to cure T1D [24], and even lower doses $(2,500$, $n=5 ; 10,000$, not shown) did not induce any therapeutic effect in the GVHD setting, and higher IL-2 doses (100,000 and 250,000 IU) significantly accelerated GVHDrelated mortality. Like us, Shin et al reported the lack therapeutic effect of IL-2 alone administration in a different genetic combination [28]. In contrast, during the 90's, pioneer work by the group of David Sachs [25-27] showed that 3 days of IL-2 administration could control GVHD development. In their studies, they used a fully allogeneic GVHD model in which spleen cells were used as the source of allogeneic T cells. Moreover, their IL-2 had a different origin (Cetus corporation) than ours (Proleukin, Chiron), and the used doses were 2 doses/day over 5 days of either 10,000 or 50,000 Cetus units, corresponding to 60,000 or $300,000 \mathrm{IU}$. To understand the origin of the different therapeutic outcome, we also tested their experimental conditions in our model. However, the graft of spleen cells instead of lymph node cells on IL-2 treated mice did not improve GVHD incidence nor did the reduction of the treatment from 10 to 3 days (data not shown). These differences suggest the key factor underlying IL-2 therapeutic outcome is likely the type of GVHD (fully allogeneic, semi allogeneic, syngeneic) [25-28].

Indeed, contrary to T1D, which is an organ-specific slowly progressive chronic inflammatory disease; acute GVHD is a highly inflammatory systemic disease implying about $10 \%$ of the donor T cell repertoire [45]. This unique scenario, in which IL-2 administration increases and prolongs CD25 expression on these numerous 
activated allogeneic T cells, likely explains the opposite outcome of low-dose IL-2 administration in GVHD compared to T1D. Indeed, functional CD25 expression endows Tcons with the capacity to compete with Tregs for low-doses of IL-2, and the selective IL-2 action on Tregs is lost. Moreover, this scenario seems valid beyond the lymphopenia associated to the conditioning of the host, as suggested by the absence of protection from GVHD in IL-2-treated non-irradiated recipient mice. Notably, CD25 expression level is a sensitive biomarker of IL-2 effects in vivo, and follow-up of CD25 expression on Tcons upon IL-2 administration may contribute to appropriately assess the side effect of Tcon activation when implementing low-dose IL-2-based therapies.

An alternative approach is illustrated by the very recent work by Ito S. at al [30] in which ultra-low dose IL-2 administration to immunocompetent healthy volunteers induced the expansion of Tregs and prompted the authors to propose said strategy for SCT donors to prevent GVHD. Here, we tested this hypothesis for the first time in mouse GVHD, and observed that although grafts obtained from IL-2 treated donors were increased in Tregs, GVHD incidence was not modified compared to mice that received unmanipulated grafts. Absence of efficacy can be explained by our previous published observations showing that acute GVHD can only be controlled by the infusion of Tregs and Tcons at a 1:1 ratio [3]. Here, we observed that IL-2 administration to donor mice could not increase Tregs more than 1,3 folds. Similarly, ultra-low dose IL-2 administration to healthy volunteers [30] induced an approximately 2-fold expansion of Tregs without activating Tcons. These IL-2 performances are still very far away from the theoretically desired more than 20-fold increase needed to approach a 1:1 Treg:Tcon ratio. 
Unlike previous experimental models [27, 28], the xeno-GVHD model used in this report uses for the first time of human cells thus reflecting probably more accurately IL-2 clinical effect on human cells and the disease process. Consequently, the results reported here are highly relevant and striking as they show that despite an increase in Tregs cells (mean 3.6\% +/- 0.57 at day 0 versus $5.60 \%+/-1.51$ at day 5 ), which is comparable to what is observed in humans following administration of low doses of IL-2 in healthy donors $(3.53 \%+/-1.17$ at day 0 versus $5.68 \%+/-1.56$ at day $4 ;$ [46]) or in allogeneic stem cell transplant recipients (4.8\% at day 0 versus $11.1 \%$ after one month of IL-2 treatment; [40]), no clinical impact was observed on GVHD. Thus, the model seems to well reflect well the Treg increases that can be expected with this therapy, which makes the ultimate finding of lack of clinical response of high clinicaltranslational value. Of note, during xeno-GVHD, expanded Tregs were unable to control the production of inflammatory cytokines by the activated Tconvs, arguing again for a lack of efficacy associated to an insufficient increase of the Treg/Teff ratio (from $0.5: 10$ to $2: 10$ ratio, far from the theoretically optimal $1: 1$ ratio) (ref 1 ), as discussed above, and in accordance with our previous observations showing that Treg content is not a reliable predictive factor of GVHD [47].

The lack of therapeutic efficacy of low-dose IL-2 in the inflammatory context of acute GVHD does not invalidate the potential use of low-dose IL-2 as an immunosuppressive agent. On the contrary, two recent clinical trials - one in chronic GVHD refractory to glucocorticoid therapy [39] and another in a prophylactic regimen in pediatric patients [29] have provided the proof of concept that low doses of IL-2 can induce Treg expansion in vivo and that may provide therapeutic benefits. However, in these trials, IL-2 was concomitantly administered with conditioning/prophylaxis regimens, which included immunosuppressive drugs, such 
as rapamycin or glucocorticoids, making it difficult to weight IL-2 alone contribution to therapeutic outcome. Indeed, a recent publication by Negrin's group, showed that efficacy of IL-2 treatment to lower GVHD in mice is only achieved if IL-2 is combined with rapamycin [28]. This strategy combines the beneficial effect of IL-2 on Tregs with concomitant elimination of the pathogenic Tcons by rapamycin [48, 49]. At odds with these results, we observed that during xeno-GVHD, addition of rapamycin to lowdose IL-2 administration was inefficient to control GVHD. One possible limitation in our model could be due to the lack of donor APC engrafting in the immunodeficient mice together with CD3 cells. Indeed, it has been recently shown that part of the effect of rapamycin was to induce an increase in IL-12 secretion by dendritic cells thus leading to INF-g-dependent apoptosis of alloreactive T cells [50]. The capacity for murine recipient dendritic cells to produce IL-12 under rapamycin treatment and to induce such effect on human T cells is unknown.

In conclusion, the use of IL-2 as an immunosuppressive drug is an emerging concept, resulting in a previously unsought clinical use of this cytokine. IL-2 was initially used at high-doses in cancer to boost the anti-tumoral immune response $[13,15]$; it is now used at low doses to slow down or even control autoimmune or chronic inflammation, probably by boosting Treg function [23, 24, 37, 39, 51-53]. However, our results obtained in the particular setting of experimental acute GVHD indicate that IL-2 effects can be radically different depending on the underlying immune pathology. Consequently, although our data documents the limitations associated to IL-2 treatment during GVHD; combination of IL-2 with other drugs that target activated conventional cells (rapamycin, MMF, etc) and definition of more appropriated settings 
such as patients receiving HSCT from matched related donors, may represent a valuable strategies to control GVHD. 


\subsection{MATERIALS AND METHODS:}

\subsubsection{Mice}

Seven- to twelve-week-old C57BL/6 (B6) (H-2b), [B6 x DBA/2] F1 (B6D2F1, H-2bxd) mice were obtained from Janvier Laboratory (France). NOD.Cg-Prkdcscid II2rgtm1Wjl ISzJ (NSG) and Luciferase-expressing (B6 luc+) mice were bred in our animal facility under specific pathogen-free conditions. Manipulations were performed according to European Union guidelines and with approval by The Ethics Committee in Animal Experiment Charles Darwin, France (Ce5/2012/021).

\subsubsection{IL-2 treatment}

Donor or recipient mice were treated with daily intraperitoneal (IP) injections of recombinant human IL-2 (Proleukin, Novartis) for 5 or 10 consecutive days as indicated. Rapamycin (Rapamune, Wyeth Laboratory) was administered per os (1.5 $\mathrm{mg} / \mathrm{kg})$.

\subsubsection{Acute GVHD model}

Acute GVHD was induced as has been described previously [3]. Briefly, eight- to twelve-week-old B6D2F1 recipient mice were lethally irradiated with $11 \mathrm{~Gy}$, given in 2 split doses of 5.5 Gy 5 hours apart, followed by an intravenous (IV) injection of 10x106 C57BL/6 donor bone marrow (BM) cells and 4x106 B6 lymph node (LN) CD3+ $T$ cells to induce GVHD. These cells were collected from donor mice LN, and the percentage of CD3+ $\mathrm{T}$ cells was determined by flow cytometry. Grafted mice were monitored for weight loss and survival 3 times per week for 2 months. A body weight loss of more than $30 \%$ of initial weight resulted in euthanasia. 


\subsubsection{Non-irradiated Acute GVHD model}

Briefly, non-irradiated eight- to twelve-week-old B6D2F1 recipient mice were injected IV with $20 \times 10^{6}$ B6 lymph node (LN) $\mathrm{CD}^{+} \mathrm{T}$ cells to induce GVHD. These cells were collected from donor mice LN, and the percentage of CD3+ T cells was determined by flow cytometry. Grafted mice were monitored for weight loss and survival 3 times per week for 80 days. A body weight loss of more than $30 \%$ of initial weight resulted in euthanasia.

\subsubsection{In vivo bioluminescent imaging (BLI)}

In vivo BLI was performed as previously described [54]. Mice received an IP injection of $30 \mu \mathrm{g} / \mathrm{g}$ of body weight of D-Luciferin (Caliper Life Sciences). Imaging of mice was done ten minutes later using an IVIS Spectrum imaging system (Caliper Life and analyzed with Living Image software (Caliper Life Sciences).

\subsubsection{Xeno-GVHD model}

Xeno-GVHD was induced as described [55]. Ten- to fifteen-week-old NOD.CgPrkdcscidII2rgtm1Wjl/SzJ (NSG) recipient mice (Charles River) received an intravenous injection of PBMCs containing $12 \times 10^{6}$ human $\mathrm{CD} 3+$ obtained from healthy volunteers with their informed consent (EFS) and monitored for weight loss and survival for 2 months. Body weight loss higher than $30 \%$ of initial weight resulted in euthanasia.

\subsubsection{Antibodies and flow cytometry}

For cells of mouse origin: anti-CD3, anti-CD4, anti-CD8, anti-CD25, anti-CD44, antiCD62L, anti-CD69, anti-GITR, anti-H-2Kb, anti-H-2Kd and anti-ICOS labeled with PE, 
APC, PerCP, FITC, PE-Cy7, AF700, V500 and biotin were purchased from BD (France). Anti-CD8 and anti-CD25 labeled with AF700, APC-H7, PE-Cy7, PerCPCy5.5,FITC and PerCP or Pacific Blue streptavidin were purchased from eBioscience (France). PE- or Pacific Blue- anti-Foxp3 staining was performed using the eBioscience kit and protocol. Events were acquired on an LSR II flow cytometer (BD Biosciences), and data were analyzed using FlowJo (Tree Star, USA).

For cells of human origin: Single cell suspensions of blood, spleens and livers were stained with anti-CD45-V500, anti-CD3-PE, anti-CD4-Alexa700 (all from BD Biosciences), anti-CD8 $\square \square$ ECD, anti-CD25-PE-Cy7 (both from Beckman Coulter) and anti-CD127-BV421 (BioLegend). For intracellular cytokine staining, cells were restimulated with PMA/lono for $3 \mathrm{~h}$ in the presence of brefeldin A (eBioscience) and stained with anti-CD45-APC-Cy7 (BD Biosciences), anti-CD3-PE-Cy5, anti-CD8 $\square$ ECD (both from Beckman Coulter) anti-CD4-APC (Miltenyi Biotech). Anti-Foxp3Alexa488, anti-IFN $\square$ PE-Cy7 (both from eBiosciences), anti-Ki67-Alexa647 and antiTNF $\square$ PE (both BD Biosciences) staining was then performed using the eBioscience Foxp3 staining kit. Events were acquired on a Fortessa flow cytometer (BD Biosciences) and data analyzed using FlowJo (Tree Star).

\subsubsection{Statistical analysis}

When comparing differences between groups, if sample distribution was normal (Shapiro-Wilk normality test) we applied a two-sided unpaired Student's $t$-test and if sample distribution was not normal we applied a two-sided non-parametric MannWhitney test. $P<0.05$ was taken as statistical significance. Survival proportions were calculated using the Kaplan-Meyer method, and statistical significances were 
calculated using the Gehan-Breslow-Wilcoxon test. A p-value <.05 was considered significant. All statistical analyses were performed using GraphPad Prism 5 software (GraphPad Software, USA).

\subsection{ACKNOWLEDGEMENTS}

This work was supported by the "Agence de la Biomédecine". LP was supported by the French Government; GHM was supported by the French Government and by the "Ligue Nationale contre le cancer". The authors acknowledge Olivier Boyer (Rouen University, France) for providing proofreading of the manuscript and useful comments. We thank the animal care team members Christelle Enond, Flora Issert, François Bodin, Serban Morosan (all from the Centre d'Exploration Fonctionnelle, Université Pierre et Marie Curie) and Olivier Lebhar, Armelle Halle, Céline Daviaud, Isabelle Grandjean and Virgine Dangles-Marie (all from the Institut Curie, Paris).

\subsection{CONFLICT OF INTEREST}

E.P. is inventor of a patent application related to the use of low-dose IL2 owned by her public institutions. There is no other conflict of interest.

\subsection{AUTHORS CONTRIBUTION}

GHM and LP performed the research, analyzed the data and wrote the paper; SM, JLC and EP designed the research, analyzed the data and wrote the paper. 


\subsection{FIGURE LEGENDS}

Figure 1. Low-dose IL-2 administration in donor mice selectively expands Tregs. (a)

(a) Experimental protocol: donor B6 mice were daily treated for 5 days with PBS or different doses of IL-2, as indicated. Lymph nodes (graft) were collected at day 0 and processed for flow cytometry analysis. (b) Foxp3 staining among $\mathrm{CD}^{+} \mathrm{T}$ cells in a representative mouse of each group. (c) Percentage of $T_{\text {reg }}$ cells (left panel) and CD25 (middle panel) and Foxp3 (right panel) mean fluorescence intensity (MFI) value among $\mathrm{T}_{\text {reg }}$ cells. Percentages and MFI are expressed as relative variation from the percentage or MFI value of the PBS group of the same experiment, which have an arbitrary value of 100. (d) Percentage of effector memory (EM, CD44 $\left.{ }^{\text {high }} \mathrm{CD}^{-} \mathrm{L}^{-}\right)$, central memory $(\mathrm{CM}$, $\left.\mathrm{CD} 44^{\text {high }} \mathrm{CD} 62 \mathrm{~L}^{+}\right)$and naïve $\left(\mathrm{N}, \mathrm{CD} 44^{\text {low/- }} \mathrm{CD} 62 \mathrm{~L}^{+}\right)$cells among $\mathrm{T}_{\text {reg }}$ cells (left panel), $\mathrm{CD}^{+} \mathrm{T}_{\text {conv }}$ (middle panel) and $\mathrm{CD}^{+} \mathrm{T}_{\text {conv }}$ cells (right). Graphs show cumulative data from 4 independent experiments. Errors bars are the S.E.M. of the mean value. ${ }^{*} P<$ $0.05 ;{ }^{* \star} P<0.01$ and ${ }^{\star \star \star} P<0.001$ as assessed by a non-parametric Mann-Withney test.

Figure 2. Low-dose IL-2 administration in donor mice does allow GVHD prevention. (a) GVHD experimental protocol: recipient B6D2F1 mice were lethally irradiated and grafted with $10.10^{6}$ B6 BM cells along with $4.10^{6}$ semi-allogeneic $\mathrm{LN} \mathrm{CD}^{+} \mathrm{T}$ cells obtained from donor B6 mice pre-treated for 5 days with daily injections of PBS or different IL-2 doses, as indicated. (b) Weight curves and (c) Kaplan-Meier survival curves of the grafted mice. Graphs show cumulative data from 3 independent experiments. Errors bars are the S.E.M. of the mean value. 
Figure 3. Low-dose IL-2 administration in recipient mice does not affect GVHD incidence. (a) GVHD experimental protocol: Recipient B6D2F1 mice were lethally irradiated and grafted with $10.10^{6}$ B6 BM cells along with $4.10^{6}$ semi-allogeneic B6 LN $\mathrm{CD}^{+} \mathrm{T}$ cells. Recipient mice were then treated for 10 days with daily injections of PBS or different doses of IL-2, as indicated. (b) Kaplan-Meier survival curves and (c) weight curves of the grafted mice. Graphs show cumulative data from 4 independent experiments. Errors bars are the S.E.M. of the mean value. ${ }^{\star} P<0.05$ and ${ }^{\star \star} P<0.01$ as assessed by a Gehan-Breslow-Wilcoxon test.

Figure 4. IL-2 administration in recipient mice does not affect reconstitution of the Tcell compartment from donor cells. B6D2F1 recipient mice were lethally irradiated and injected with $10 \times 10^{6} \mathrm{BM}$ cells along with $4 \times 10^{6} \mathrm{LuC}^{+} \mathrm{CD}^{+}$cells from $\mathrm{B} 6 \mathrm{LuC}^{+}$ donor mice (a) or from wild type B6 mice (b-d). Recipient mice were then treated for 10 days with daily injections of PBS or different doses of IL-2, as indicated. (a) Representative pictures of bioluminescence activity in mice treated with PBS $(n=5)$ or 25,000 IU IL-2 ( $n=5$ ) (left panel). Average radiances of total body (top right panel) or abdomen (bottom right panel) at different days post-graft. (b-d) Kinetics of donor T cell reconstitution in B6D2F1 recipients was assessed at different time points after grafting. (b) Gating strategy used to identify donor $\mathrm{CD}^{+} \mathrm{T}_{\text {conv }}$ cells $\left(\mathrm{H}_{2} \mathrm{Kd}^{-} \mathrm{CD} 8^{+}\right)$, $\mathrm{CD}^{+} \mathrm{T}_{\text {conv }}$ cells $\left(\mathrm{H}_{2} \mathrm{Kd}^{-} \mathrm{CD}^{+}{ }^{+}\right.$Foxp3 $)$and $\mathrm{T}_{\text {reg }}$ cells $\left({\mathrm{H} 2 \mathrm{Kd}^{-} \mathrm{CD}^{+} \text {Foxp3 }}^{+}\right)$. (c-d) Percentage (c) and absolute numbers (d) of $\mathrm{T}_{\text {reg }}$ cells (left panels), $\mathrm{CD}^{+} \mathrm{T}_{\text {conv }}$ (middle panels) and $\mathrm{CD}^{+} \mathrm{T}_{\text {conv }}$ cells (right panels) in the $\mathrm{LNs}$ of recipient mice treated with PBS or different doses of IL-2, as indicated. Graphs show cumulative data from 2 independent experiments with a total of 5 (a) to 8 (c-d) mice per group. Errors bars are the S.E.M. of the mean value. 
Figure 5. IL-2 administration over-activates allogeneic donor T cells. Recipient B6D2F1 mice were treated as described in Figure 3. Splenocytes were collected and stained for flow cytometry analysis on day 6 after the graft. (a) Representative dot plots of CD44/CD62L staining among donor $C D 4^{+} \mathrm{T}_{\text {conv }}$ (top panels) and $\mathrm{CD}^{+} \mathrm{T}_{\text {conv }}$ cells (bottom panels). Numbers in quadrants represent the percentage of each population. (b) Percentage of effector memory (EM, CD44 $\left.{ }^{\text {high }} \mathrm{CD6} 2 \mathrm{~L}^{-}\right)$and naïve (N, CD44 ${ }^{\text {low/- }} \mathrm{CD} 6 \mathrm{~L}^{+}$) cells among donor $\mathrm{CD}^{+} \mathrm{T}_{\text {conv }}$ (top panels) and $\mathrm{CD}^{+} \mathrm{T}_{\text {conv }}$ cells (bottom panels). (c-d) Representative histograms of ICOS (c) and GITR (d) staining among donor $C D 4^{+} \mathrm{T}_{\text {conv }}$ (top panels) and $\mathrm{CD}^{+} \mathrm{T}_{\text {conv }}$ cells (bottom panels). ICOS (c) and GITR (d) mean fluorescence intensity (MFI) value among donor CD4 ${ }^{+} \mathrm{T}_{\text {conv }}$ (top panels) and $\mathrm{CD}^{+} \mathrm{T}_{\text {conv }}$ cells (bottom panels). MFI values are expressed as relative variation from the MFI value of the PBS group of the same experiment, which have an arbitrary value of 100. Graphs show cumulative data from 3 independent experiments. Errors bars are the S.E.M. of the mean value. ${ }^{*} P<0.05$ as assessed by a non-parametric Mann-Withney test.

Figure 6. IL-2 administration sustains CD25 expression on pathogenic donor T cells. Recipient B6D2F1 mice were treated as described in Figure 3. Splenocytes were collected and stained for flow cytometry analysis at different time points (days 0, 3, 6 and 9) after the graft. (a) Representative histograms of CD25 expression among donor $\mathrm{CD}^{+} \mathrm{T}_{\text {conv }}$ (left panel) and $\mathrm{CD}^{+} \mathrm{T}_{\text {conv }}$ cells (right panel). (b) Percentage of $\mathrm{CD}^{+} 5^{+}$cells among donor $\mathrm{CD} 4^{+} \mathrm{T}_{\text {conv }}$ (left panel) and $\mathrm{CD}^{+} \mathrm{T}_{\text {conv }}$ cells (right panel). (c) Relative MFI of CD25 among donor $\mathrm{CD}^{+} \mathrm{CD}^{+} 5^{+} \mathrm{T}_{\text {conv }}$ (left panel) and $\mathrm{CD} 8^{+}$ $\mathrm{CD}^{2} 5^{+} \mathrm{T}_{\text {conv }}$ cells (right panel). MFI values are expressed as relative variation from the MFI value of the PBS group of the same experiment, which have an arbitrary value of 
100. Graphs show cumulative data from 3 independent experiments. Errors bars are the S.E.M. of the mean value. ${ }^{\star} P<0.05 ;{ }^{\star \star} P<0.01$ and ${ }^{\star \star \star} P<0.001$ as assessed by a non-parametric Mann-Withney test.

Figure 7. Low doses IL-2 selectively expand human $T_{\text {reg }}$ cells during xenogeneic GVHD. Recipient NSG mice were grafted with $12.10^{6}$ human PBMCs and then daily treated for 10 days with PBS or different doses of IL-2, as indicated. Blood, liver and spleen were collected at various days post-graft and processed for flow cytometry analysis. (a) Percentage of $\mathrm{T}_{\text {reg }}$ cells $\left(\mathrm{CD} 25^{\text {high }}\right.$ Foxp3 $^{+}$) among donor $\mathrm{CD} 4^{+} \mathrm{T}$ cells (top) and percentage of $\mathrm{Ki}^{+} 7^{+}$cells among donor $\mathrm{T}_{\text {reg }}$ cells (bottom) in the blood of the grafted mice. (b) Percentage of $\mathrm{CD}^{2} 5^{+}$cells (top panels) and Ki67 ${ }^{+}$cells (bottom panels) among donor $\mathrm{CD}^{+} \mathrm{T}_{\text {conv }}$ (left panels) and $\mathrm{CD}^{+} \mathrm{T}_{\text {conv }}$ cells (right panels) in the blood of the grafted mice. (c) Representative histograms (top panels) and quantification (bottom panels) of IFN $\gamma$ and $\mathrm{TNF} \alpha$ production by donor $\mathrm{CD}^{+} \mathrm{T}_{\text {conv }}$ (left panels) and $\mathrm{CD}^{+} \mathrm{T}_{\text {conv }}$ cells (right panels) in the liver and spleen of the grafted mice $4 \mathrm{~h}$ after PMA/lonomycin stimulation. Graphs show cumulative data from 2 independent experiments (a-b) or are from one experiment with 4 mice per group (c). Symbols represent individual mice and horizontal bars are the medians. ${ }^{*} P<0.05 ;{ }^{*} P<0.01$ and ${ }^{* * *} P<0.001$ as assessed by a non-parametric Mann-Whitney test.

Figure 8. Treatment with low-doses of IL-2 alone or combined to rapamycin fails to ameliorate xenogeneic GVHD. (a) Xenogeneic GVHD experimental protocol: recipient NSG mice were grafted with $12.10^{6} \mathrm{CD}^{+}$PBMCs and then daily treated with PBS; 25,000 IU rhIL-2; 250,000 IU rhlL-2, 1.5 mg/kg rapamycin (Rapa) or 25,000 IU rhIL-2 and $1.5 \mathrm{mg} / \mathrm{kg}$ Rapa (IL-2/Rapa). (b) Kaplan-Meier survival curves of the grafted mice. 
Graphs show cumulative data from 5 experiments (3 with PBS and IL-2 treatment only and 2 with PBS, IL-2, Rapa and IL-2/Rapa treatment). Errors bars are the S.E.M. of the mean value. ${ }^{*} P<0.05$ as assessed by a Gehan-Breslow-Wilcoxon test. 


\subsection{REFERENCES}

1. Ferrara, JL, Levine, JE, Reddy, P, and Holler, E (2009). Graft-versushost disease. Lancet 373: 1550-1561.

2. Juvet, SC, Whatcott, AG, Bushell, AR, and Wood, KJ (2014). Harnessing regulatory $\mathrm{T}$ cells for clinical use in transplantation: the end of the beginning. American journal of transplantation : official journal of the American Society of Transplantation and the American Society of Transplant Surgeons 14: $750-763$.

3. Cohen, JL, Trenado, A, Vasey, D, Klatzmann, D, and Salomon, BL (2002). CD4(+)CD25(+) immunoregulatory T Cells: new therapeutics for graftversus-host disease. The Journal of experimental medicine 196: 401-406.

4. Hoffmann, P, Ermann, J, Edinger, M, Fathman, CG, and Strober, S (2002). Donor-type CD4(+)CD25(+) regulatory T cells suppress lethal acute graft-versus-host disease after allogeneic bone marrow transplantation. The Journal of experimental medicine 196: 389-399.

5. Taylor, PA, Lees, CJ, and Blazar, BR (2002). The infusion of ex vivo activated and expanded CD4(+)CD25(+) immune regulatory cells inhibits graft-versus-host disease lethality. Blood 99: 3493-3499.

6. Trenado, A, Charlotte, F, Fisson, S, Yagello, M, Klatzmann, D, Salomon, BL, et al. (2003). Recipient-type specific CD4+CD25+ regulatory T cells favor immune reconstitution and control graft-versus-host disease while maintaining graft-versus-leukemia. The Journal of clinical investigation 112: 1688-1696.

7. Gaidot, A, Landau, DA, Martin, GH, Bonduelle, O, Grinberg-Bleyer, Y, Matheoud, D, et al. (2011). Immune reconstitution is preserved in 
hematopoietic stem cell transplantation coadministered with regulatory $T$ cells for GVHD prevention. Blood 117: 2975-2983.

8. Martin, GH, Gregoire, S, Landau, DA, Pilon, C, Grinberg-Bleyer, Y, Charlotte, F, et al. (2013). In vivo activation of transferred regulatory $T$ cells specific for third-party exogenous antigen controls GVH disease in mice. European journal of immunology 43: 2263-2272.

9. Landwehr-Kenzel, S, Issa, F, Luu, SH, Schmuck, M, Lei, H, Zobel, A, et al. (2014). Novel GMP-compatible protocol employing an allogeneic B cell bank for clonal expansion of allospecific natural regulatory $\mathrm{T}$ cells. American journal of transplantation : official journal of the American Society of Transplantation and the American Society of Transplant Surgeons 14: 594606.

10. Putnam, AL, Safinia, N, Medvec, A, Laszkowska, M, Wray, M, Mintz, MA, et al. (2013). Clinical grade manufacturing of human alloantigen-reactive regulatory $\mathrm{T}$ cells for use in transplantation. American journal of transplantation : official journal of the American Society of Transplantation and the American Society of Transplant Surgeons 13: 3010-3020.

11. Morgan, DA, Ruscetti, FW, and Gallo, R (1976). Selective in vitro growth of T lymphocytes from normal human bone marrows. Science 193: 1007-1008.

12. Smith, KA, Gilbride, KJ, and Favata, MF (1980). Lymphocyte activating factor promotes T-cell growth factor production by cloned murine lymphoma cells. Nature 287: 853-855. 
13. Ahmadzadeh, M, and Rosenberg, SA (2006). IL-2 administration increases CD4+ CD25(hi) Foxp3+ regulatory T cells in cancer patients. Blood 107: 2409-2414.

14. Levy, Y, Durier, C, Krzysiek, R, Rabian, C, Capitant, C, Lascaux, AS, et al. (2003). Effects of interleukin-2 therapy combined with highly active antiretroviral therapy on immune restoration in HIV-1 infection: a randomized controlled trial. Aids 17: 343-351.

15. Rosenberg, SA, Yang, JC, Topalian, SL, Schwartzentruber, DJ, Weber, JS, Parkinson, DR, et al. (1994). Treatment of 283 consecutive patients with metastatic melanoma or renal cell cancer using high-dose bolus interleukin 2 . JAMA : the journal of the American Medical Association 271: 907-913.

16. Weiss, L, Letimier, FA, Carriere, M, Maiella, S, Donkova-Petrini, V, Targat, B, et al. (2010). In vivo expansion of naive and activated CD4+CD25+FOXP3+ regulatory $\mathrm{T}$ cell populations in interleukin-2-treated HIV patients. Proceedings of the National Academy of Sciences of the United States of America 107: 10632-10637.

17. Zhang, H, Chua, KS, Guimond, M, Kapoor, V, Brown, MV, Fleisher, TA, et al. (2005). Lymphopenia and interleukin-2 therapy alter homeostasis of CD4+CD25+ regulatory T cells. Nature medicine 11: 1238-1243.

18. Malek, TR (2008). The biology of interleukin-2. Annual review of immunology 26: 453-479.

19. Sadlack, B, Merz, H, Schorle, H, Schimpl, A, Feller, AC, and Horak, I (1993). Ulcerative colitis-like disease in mice with a disrupted interleukin-2 gene. Cell 75: 253-261. 
20. Suzuki, H, Kundig, TM, Furlonger, C, Wakeham, A, Timms, E, Matsuyama, T, et al. (1995). Deregulated T cell activation and autoimmunity in mice lacking interleukin-2 receptor beta. Science 268: 1472-1476.

21. Papiernik, M, de Moraes, ML, Pontoux, C, Vasseur, F, and Penit, C (1998). Regulatory CD4 T cells: expression of IL-2R alpha chain, resistance to clonal deletion and IL-2 dependency. International immunology 10: 371-378.

22. Scheffold, A, Huhn, J, and Hofer, T (2005). Regulation of CD4+CD25+ regulatory $\mathrm{T}$ cell activity: it takes (IL-)two to tango. European journal of immunology 35: 1336-1341.

23. Tang, Q, Adams, JY, Penaranda, C, Melli, K, Piaggio, E, Sgouroudis, E, et al. (2008). Central role of defective interleukin-2 production in the triggering of islet autoimmune destruction. Immunity 28: 687-697.

24. Grinberg-Bleyer, Y, Baeyens, A, You, S, Elhage, R, Fourcade, G, Gregoire, S, et al. (2010). IL-2 reverses established type 1 diabetes in NOD mice by a local effect on pancreatic regulatory $\mathrm{T}$ cells. The Journal of experimental medicine 207: 1871-1878.

25. Sykes, M, Abraham, VS, Harty, MW, and Pearson, DA (1993). IL-2 reduces graft-versus-host disease and preserves a graft-versus-leukemia effect by selectively inhibiting CD4+ T cell activity. Journal of immunology 150: 197-205.

26. Sykes, M, Romick, ML, Hoyles, KA, and Sachs, DH (1990). In vivo administration of interleukin 2 plus T cell-depleted syngeneic marrow prevents graft-versus-host disease mortality and permits alloengraftment. The Journal of experimental medicine 171: 645-658. 
27. Sykes, M, Romick, ML, and Sachs, DH (1990). Interleukin 2 prevents graft-versus-host disease while preserving the graft-versus-leukemia effect of allogeneic T cells. Proceedings of the National Academy of Sciences of the United States of America 87: 5633-5637.

28. Shin, HJ, Baker, J, Leveson-Gower, DB, Smith, AT, Sega, EI, and Negrin, RS (2011). Rapamycin and IL-2 reduce lethal acute graft-versus-host disease associated with increased expansion of donor type CD4+CD25+Foxp3+ regulatory T cells. Blood 118: 2342-2350.

29. Kennedy-Nasser, A, Ku, S, Castillo-Caro, P, Hazrat, Y, Wu, MF, Liu, H, et al. (2014). Ultra Low-Dose IL-2 for GVHD prophylaxis after Allogeneic HSCT mediates Expansion of Regulatory T Cells Without Diminishing Antiviral and Anti-leukemic Activity. Clinical cancer research : an official journal of the American Association for Cancer Research.

30. Ito, S, Bollard, CM, Carlsten, M, Melenhorst, JJ, Biancotto, A, Wang, E, et al. (2014). Ultra-low Dose Interleukin-2 Promotes Immune-modulating Function of Regulatory T Cells and Natural Killer Cells in Healthy Volunteers. Molecular therapy : the journal of the American Society of Gene Therapy 22: 1388-1395.

31. Zeiser, R, Nguyen, VH, Beilhack, A, Buess, M, Schulz, S, Baker, J, et al. (2006). Inhibition of CD4+CD25+ regulatory T-cell function by calcineurindependent interleukin-2 production. Blood 108: 390-399.

32. Maury, S, Salomon, B, Klatzmann, D, and Cohen, JL (2001). Division rate and phenotypic differences discriminate alloreactive and nonalloreactive $\mathrm{T}$ cells transferred in lethally irradiated mice. Blood 98: 3156-3158. 
33. Long, M, and Adler, AJ (2006). Cutting edge: Paracrine, but not autocrine, IL-2 signaling is sustained during early antiviral CD4 T cell response. Journal of immunology 177: 4257-4261.

34. Yu, A, Zhu, L, Altman, NH, and Malek, TR (2009). A low interleukin-2 receptor signaling threshold supports the development and homeostasis of $\mathrm{T}$ regulatory cells. Immunity 30: 204-217.

35. Kalia, V, Sarkar, S, Subramaniam, S, Haining, WN, Smith, KA, and Ahmed, R (2010). Prolonged interleukin-2Ralpha expression on virus-specific CD8+ T cells favors terminal-effector differentiation in vivo. Immunity 32: 91103.

36. Pickel, K, and Hoffmann, MK (1977). Suppressor T cells arising in mice undergoing a graft-vs-host response. Journal of immunology 118: 653-656.

37. Saadoun, D, Rosenzwajg, M, Joly, F, Six, A, Carrat, F, Thibault, V, et al. (2011). Regulatory T-cell responses to low-dose interleukin-2 in HCV-induced vasculitis. The New England journal of medicine 365: 2067-2077.

38. Hartemann, A, Bensimon, G, Payan, CA, Jacqueminet, S, Bourron, O, Nicolas, $\mathrm{N}$, et al. (2013). Low-dose interleukin 2 in patients with type 1 diabetes: a phase 1/2 randomised, double-blind, placebo-controlled trial. The lancet Diabetes \& endocrinology 1: 295-305.

39. Koreth, J, Matsuoka, K, Kim, HT, McDonough, SM, Bindra, B, Alyea, EP, 3rd, et al. (2011). Interleukin-2 and regulatory T cells in graft-versus-host disease. The New England journal of medicine 365: 2055-2066.

40. Kennedy-Nasser, AA, Ku, S, Castillo-Caro, P, Hazrat, Y, Wu, MF, Liu, H, et al. (2014). Ultra Low-Dose IL-2 for GVHD Prophylaxis after Allogeneic 
Hematopoietic Stem Cell Transplantation Mediates Expansion of Regulatory $\mathrm{T}$ Cells without Diminishing Antiviral and Antileukemic Activity. Clin Cancer Res. 41. Cooke, KR, Hill, GR, Crawford, JM, Bungard, D, Brinson, YS, Delmonte, J, Jr., et al. (1998). Tumor necrosis factor- alpha production to lipopolysaccharide stimulation by donor cells predicts the severity of experimental acute graft-versus-host disease. J Clin Invest 102: 1882-1891.

42. Mowat, AM (1989). Antibodies to IFN-gamma prevent immunologically mediated intestinal damage in murine graft-versus-host reaction. Immunology 68: $18-23$.

43. Hannon, M, Lechanteur, C, Lucas, S, Somja, J, Seidel, L, Belle, L, et al. (2014). Infusion of clinical-grade enriched regulatory $T$ cells delays experimental xenogeneic graft-versus-host disease. Transfusion 54: 353-363.

44. Parmar, S, Liu, X, Tung, SS, Robinson, SN, Rodriguez, G, Cooper, LJ, et al. (2014). Third-party umbilical cord blood-derived regulatory $\mathrm{T}$ cells prevent xenogenic graft-versus-host disease. Cytotherapy 16: 90-100.

45. Shlomchik, WD (2007). Graft-versus-host disease. Nature reviews Immunology 7: 340-352.

46. Ito, S, Bollard, CM, Carlsten, M, Melenhorst, JJ, Biancotto, A, Wang, E, et al. (2014). Ultra-low dose interleukin-2 promotes immune-modulating function of regulatory $\mathrm{T}$ cells and natural killer cells in healthy volunteers. Mol Ther.

47. Rosenzwajg, M, Dhedin, N, Maury, S, Bensimon, G, Landau, DA, Norol, F, et al. (2010). Regulatory T cell content in the bone marrow graft does not predict the occurrence of acute GVHD. Biol Blood Marrow Transplant. 
48. Battaglia, M, Stabilini, A, Migliavacca, B, Horejs-Hoeck, J, Kaupper, T, and Roncarolo, MG (2006). Rapamycin promotes expansion of functional CD4+CD25+FOXP3+ regulatory T cells of both healthy subjects and type 1 diabetic patients. Journal of immunology 177: 8338-8347.

49. Battaglia, M, Stabilini, A, and Roncarolo, MG (2005). Rapamycin selectively expands CD4+CD25+FoxP3+ regulatory T cells. Blood 105: 47434748.

50. Stenger, EO, Rosborough, BR, Mathews, LR, Ma, H, Mapara, MY, Thomson, AW, et al. (2014). IL-12hi rapamycin-conditioned dendritic cells mediate IFN-gamma-dependent apoptosis of alloreactive CD4+ T cells in vitro and reduce lethal graft-versus-host disease. Biol Blood Marrow Transplant 20: $192-201$.

51. Koulmanda, M, Budo, E, Bonner-Weir, S, Qipo, A, Putheti, P, Degauque, N, et al. (2007). Modification of adverse inflammation is required to cure new-onset type 1 diabetic hosts. Proceedings of the National Academy of Sciences of the United States of America 104: 13074-13079.

52. Webster, KE, Walters, S, Kohler, RE, Mrkvan, T, Boyman, O, Surh, CD, et al. (2009). In vivo expansion of $\mathrm{T}$ reg cells with IL-2-mAb complexes: induction of resistance to EAE and long-term acceptance of islet allografts without immunosuppression. The Journal of experimental medicine 206: 751760.

53. Wilson, MS, Pesce, JT, Ramalingam, TR, Thompson, RW, Cheever, A, and Wynn, TA (2008). Suppression of murine allergic airway disease by IL2:anti-IL-2 monoclonal antibody-induced regulatory $\mathrm{T}$ cells. Journal of immunology 181: 6942-6954. 
54. Duda, J, Karimi, M, Negrin, RS, and Contag, CH (2007). Methods for imaging cell fates in hematopoiesis. Methods in molecular medicine 134: 1734.

55. Ito, R, Katano, I, Kawai, K, Hirata, H, Ogura, T, Kamisako, T, et al. (2009). Highly sensitive model for xenogenic GVHD using severe immunodeficient NOG mice. Transplantation 87: 1654-1658. 
Figure 1

a

- PBS

or

- IL-2 $(25,000$ IU

to $250,000 \mathrm{IU})$

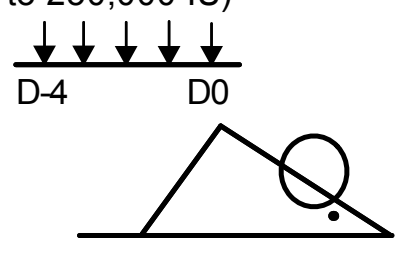

Donor B6

C

$\square$ PBS

25,000 IU IL-2

50,000 IU IL-2

100,000 IU IL-2

250,000 IU IL-2

d

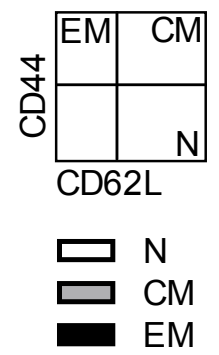

b

Gated on $\mathrm{CD} 4^{+}$
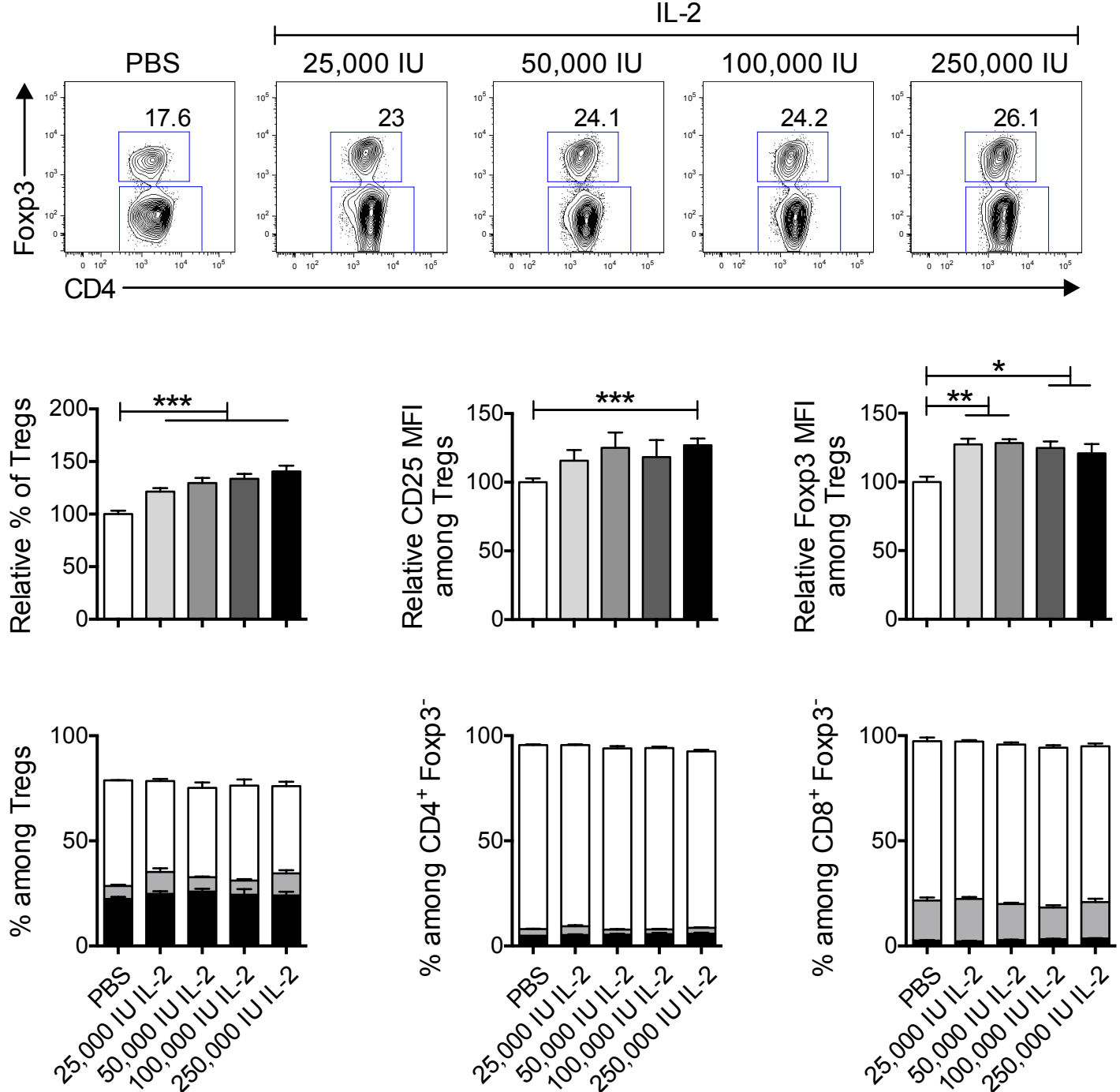
Figure 2

a

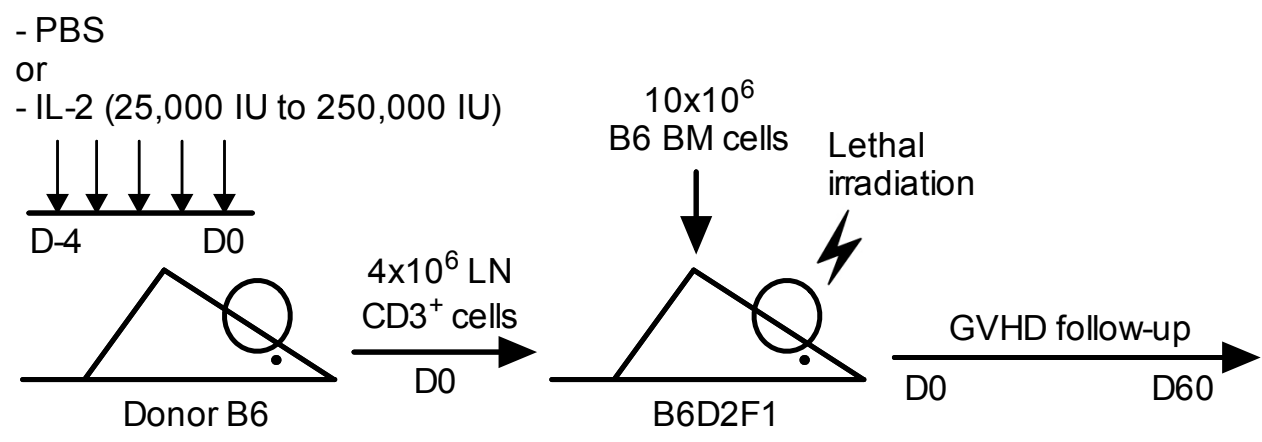

b

PBS (n=11)

A. 25,000 IU IL-2 ( $n=7)$

$-\nabla-50,000$ IU IL-2 (n=7)

$\checkmark 100,000$ IU IL-2 $(n=11)$

... 250,000 IU IL-2 ( $n=8)$
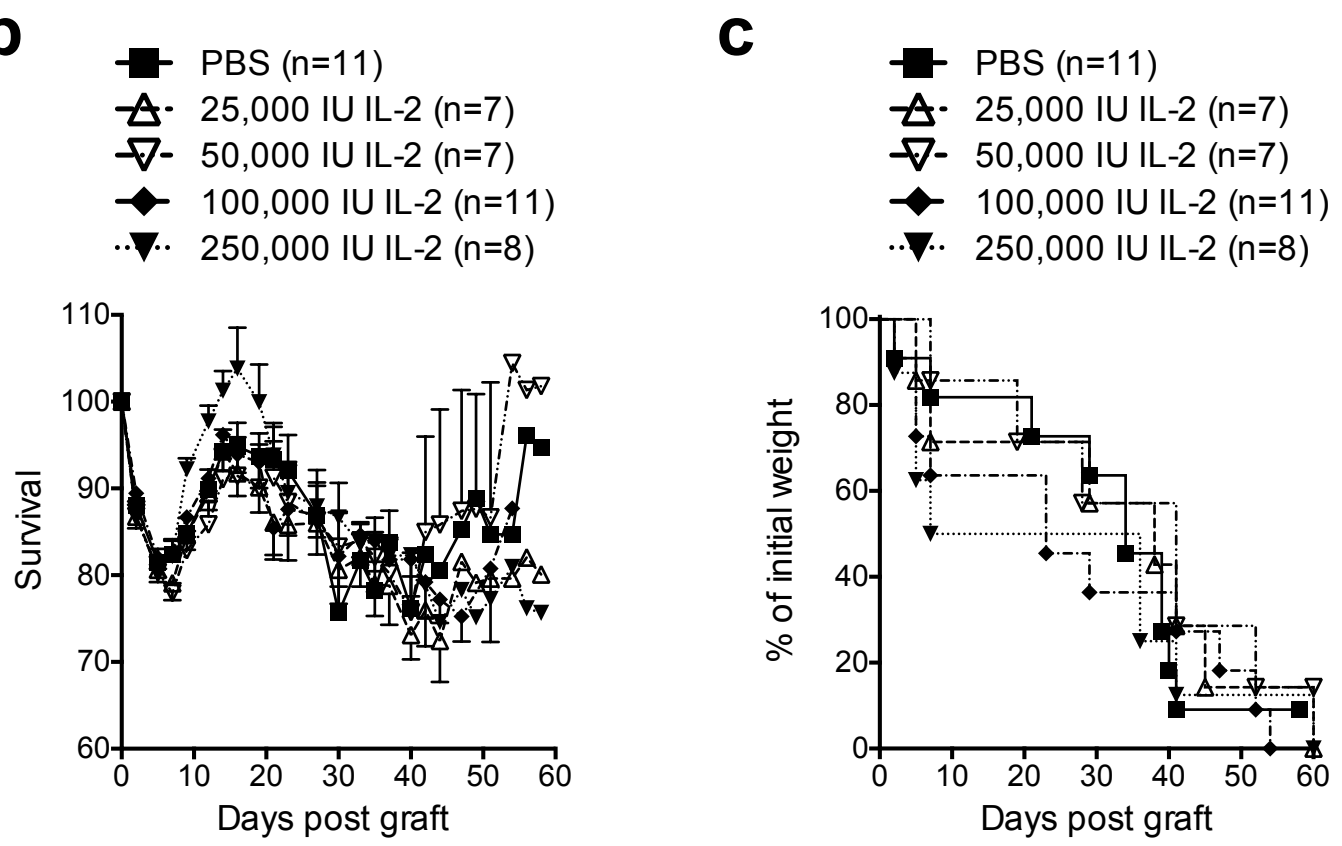


\section{Figure 3}

a

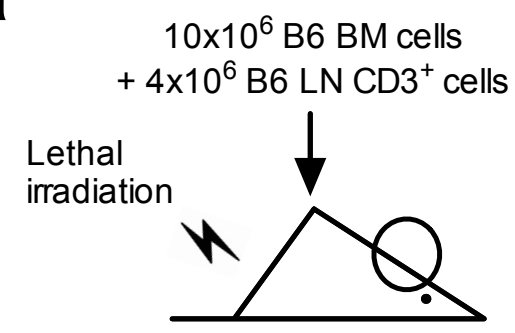

$$
\text { - PBS }
$$

or

- IL-2 (25,000 IU; 100,000 IU or 250,000 IU)

B6D2F1
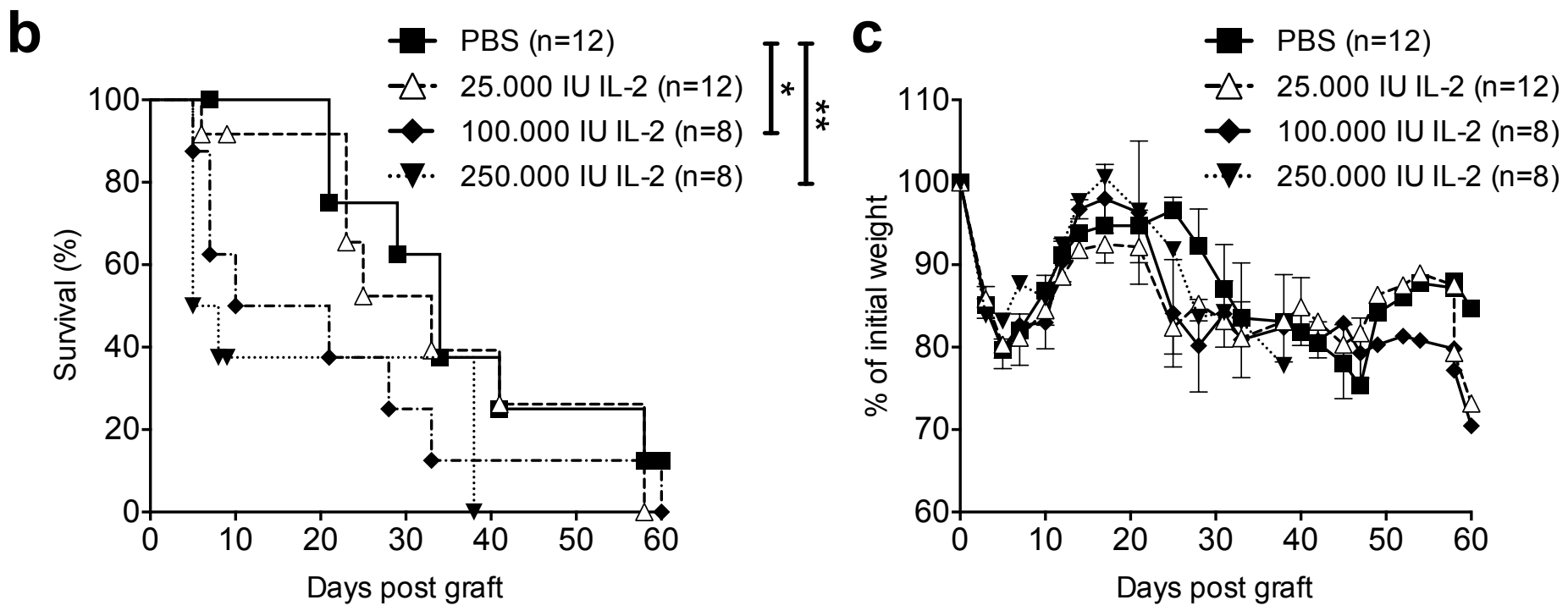


\section{Figure 4}

a
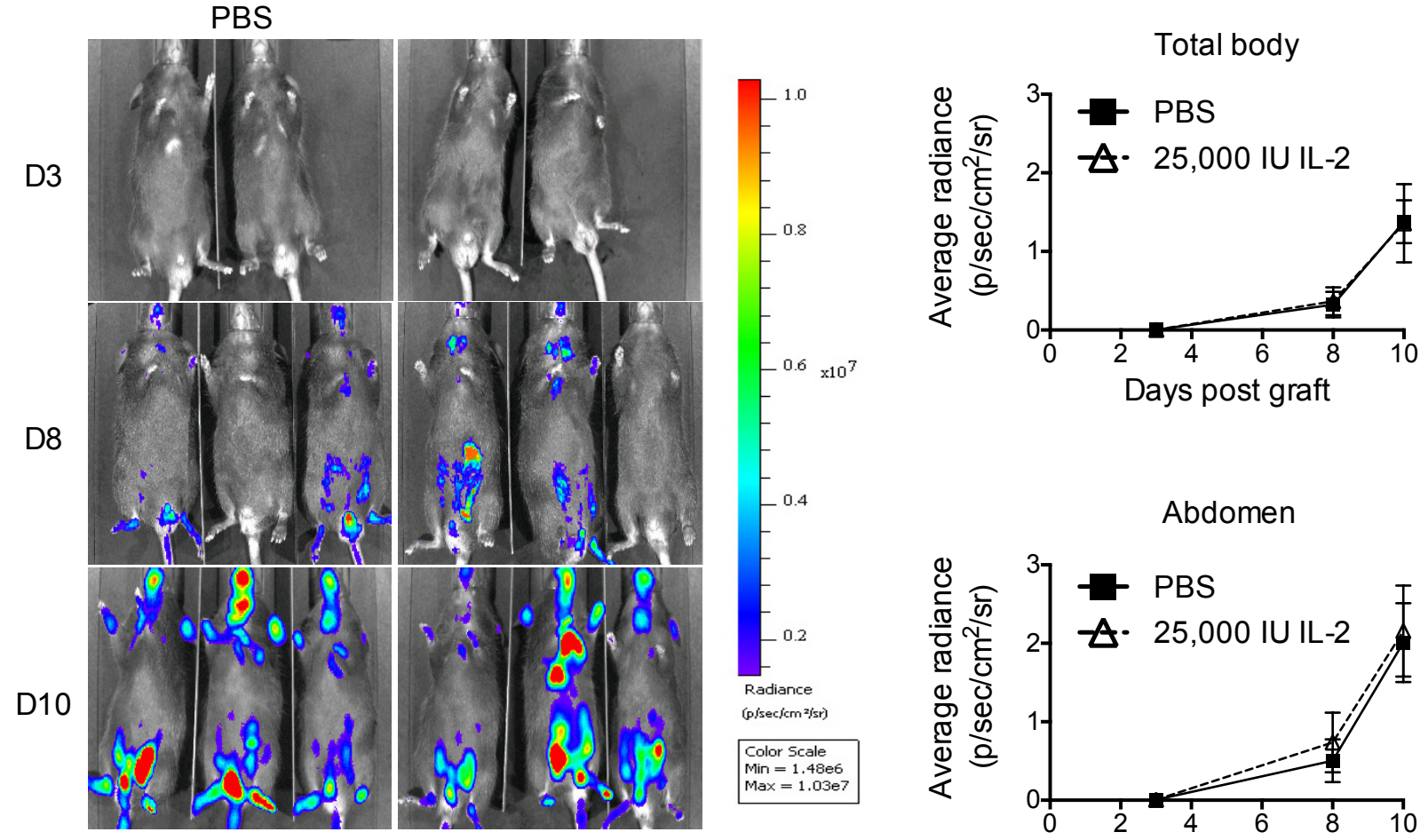

b
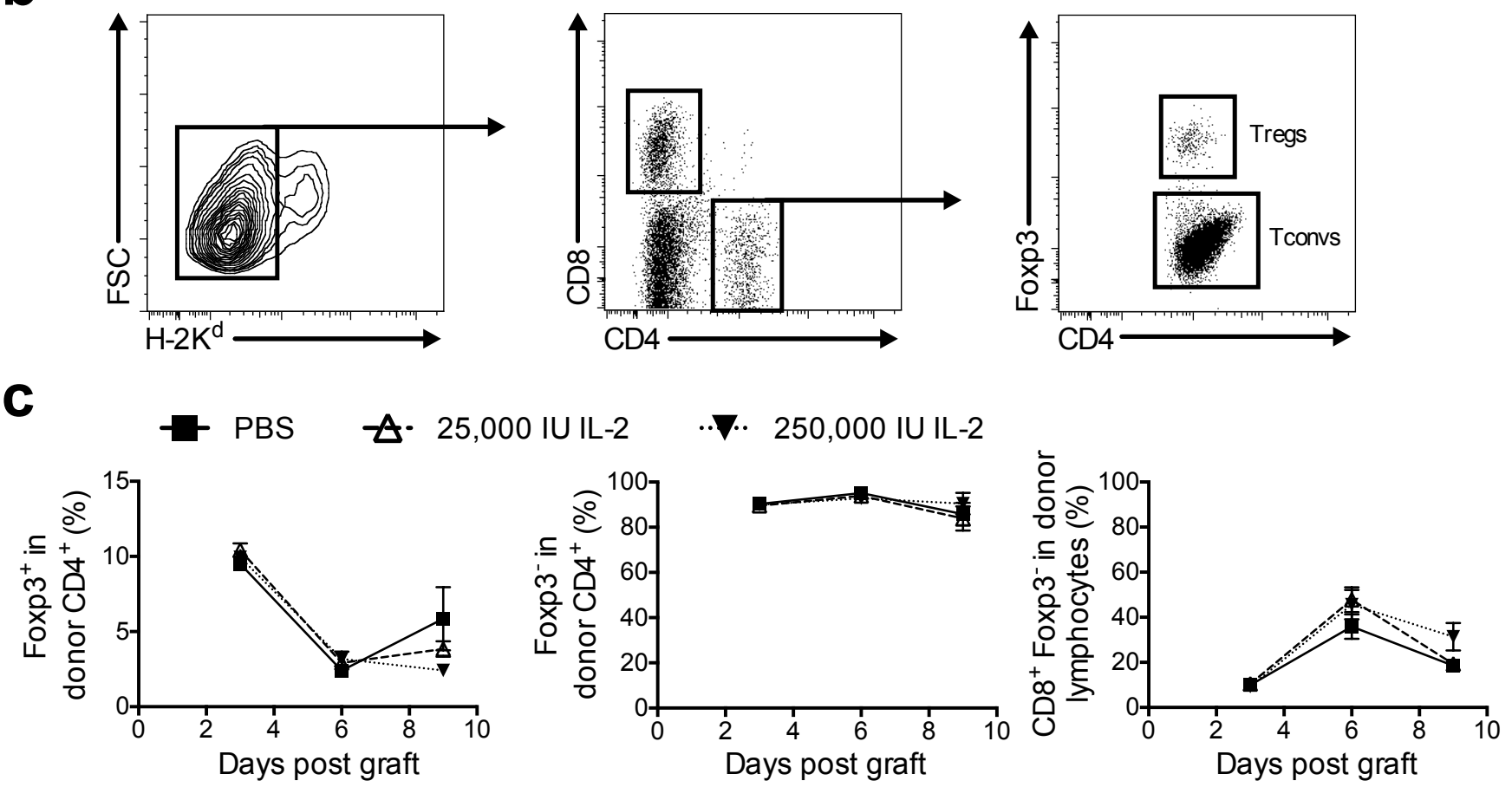

d

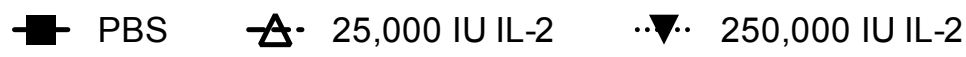
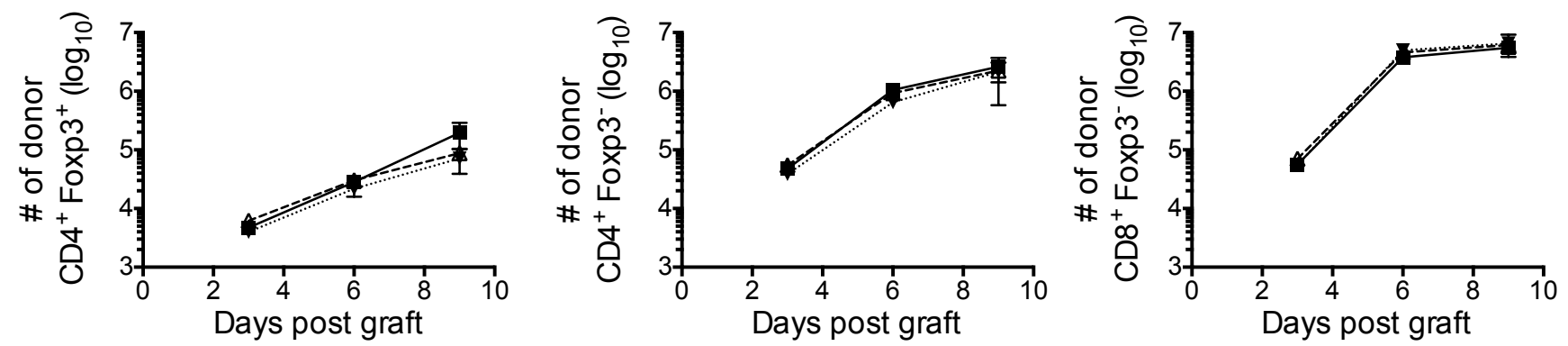


\section{Figure 5}
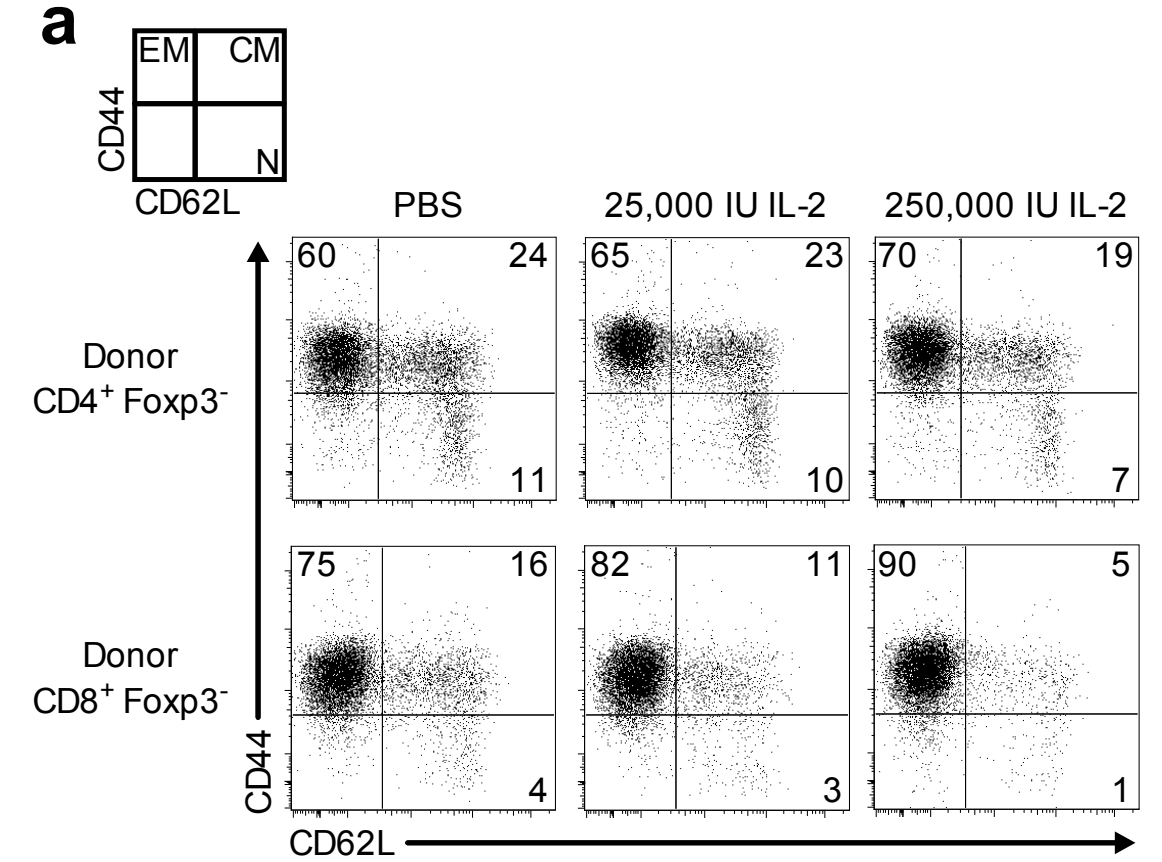

CD62L

C
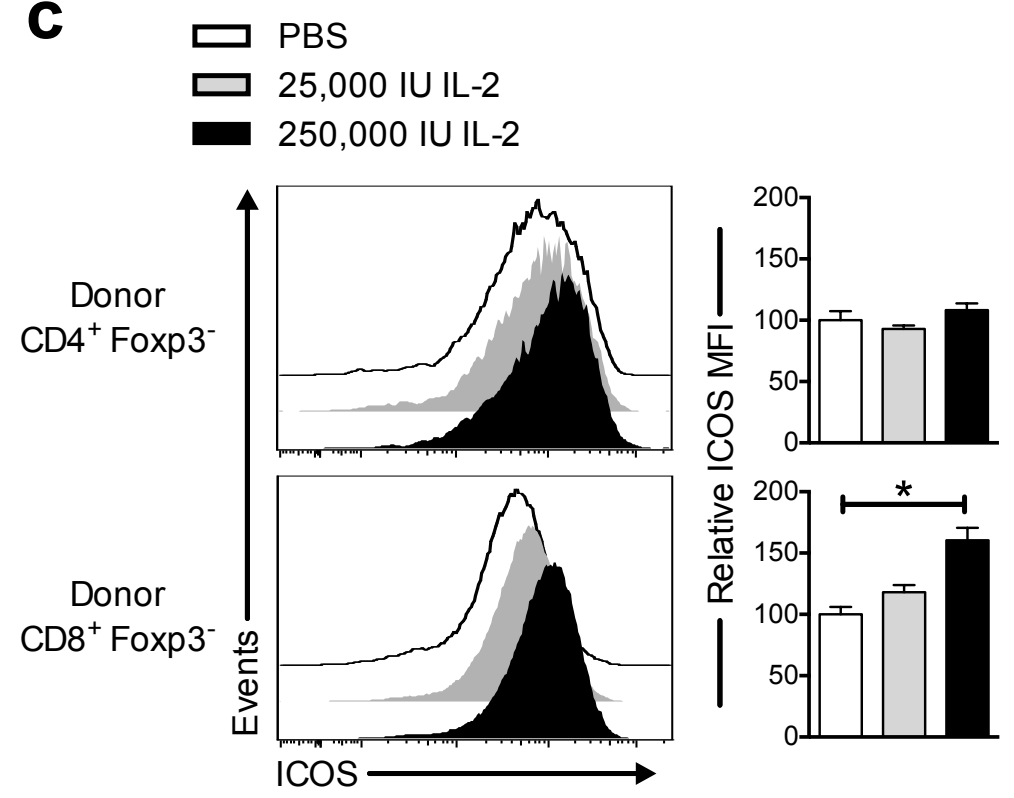

b

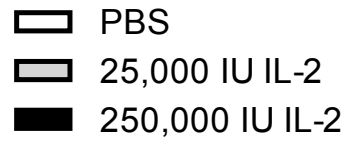

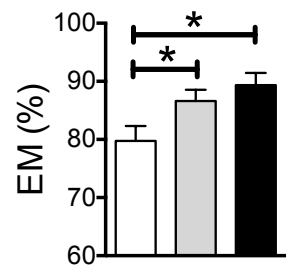
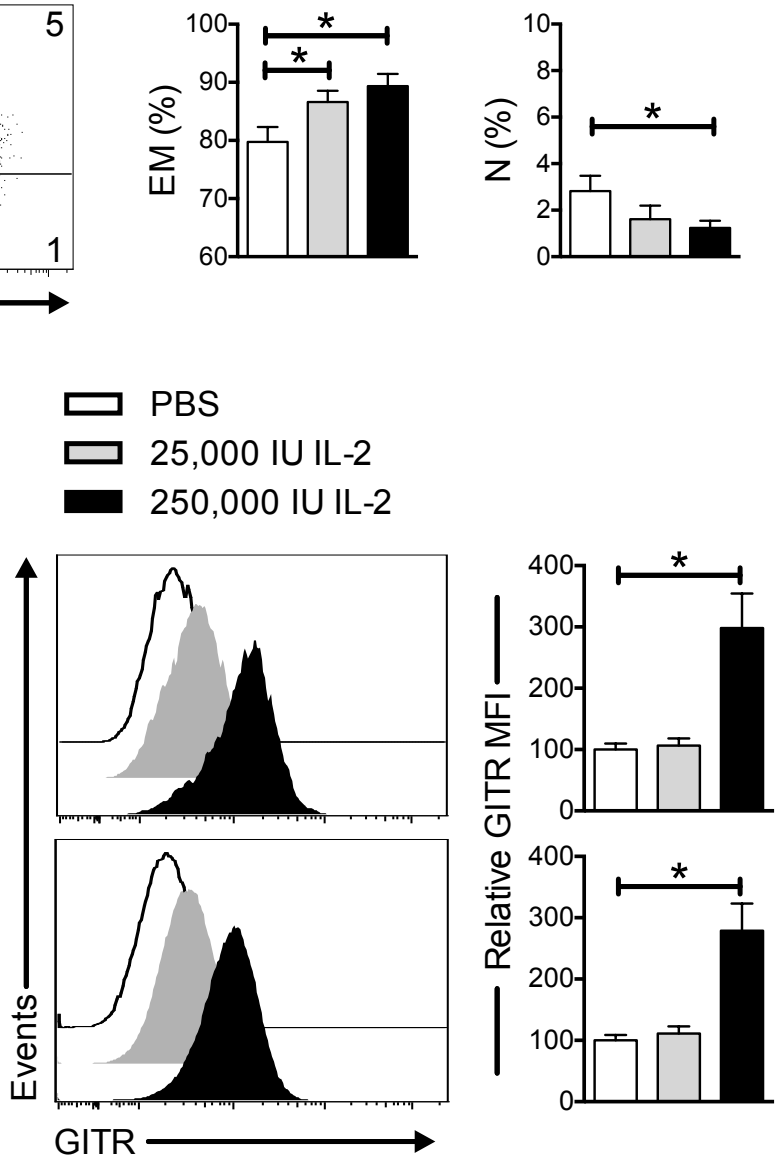

GITR 


\section{Figure 6}

a

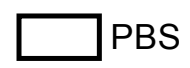

250,000 IU IL-2

Donor CD4 ${ }^{+}$Foxp3

Do
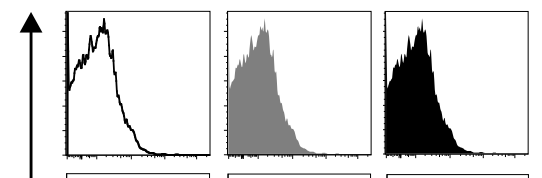

D3
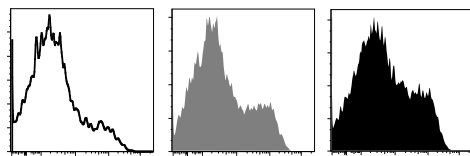

D6
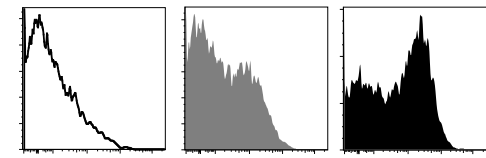

D9
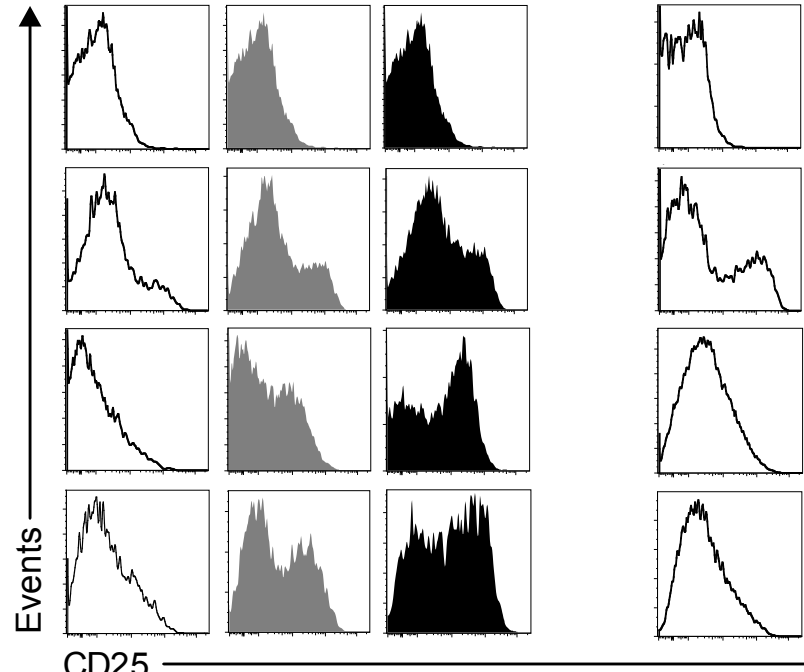

Donor CD8 ${ }^{+}$Foxp3 $3^{-}$
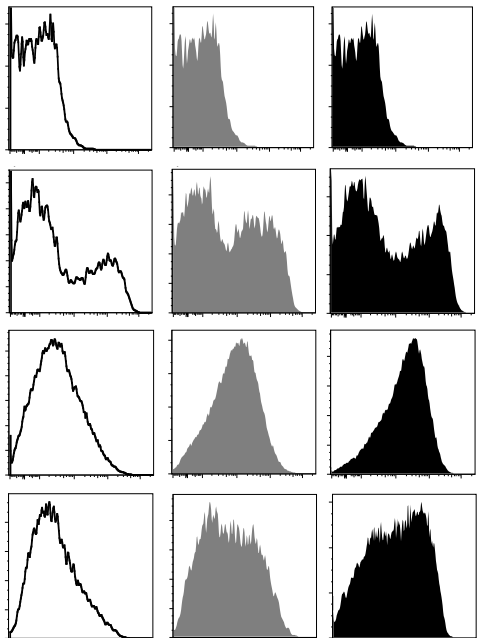

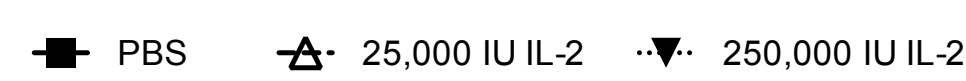

b Donor $\mathrm{CD}^{+}{ }^{+}$Foxp3 -

Donor CD8 ${ }^{+}$Foxp3-
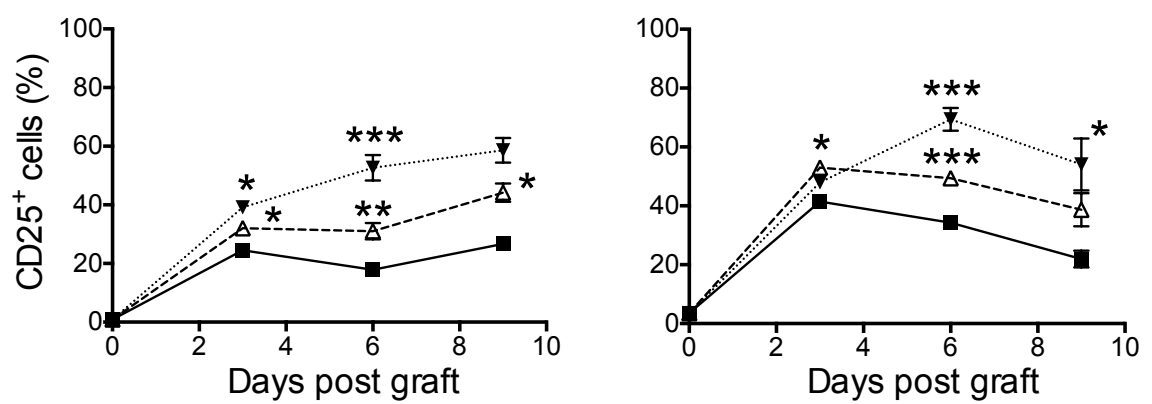

C

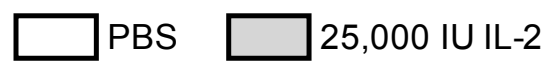

250,000 IU IL-2
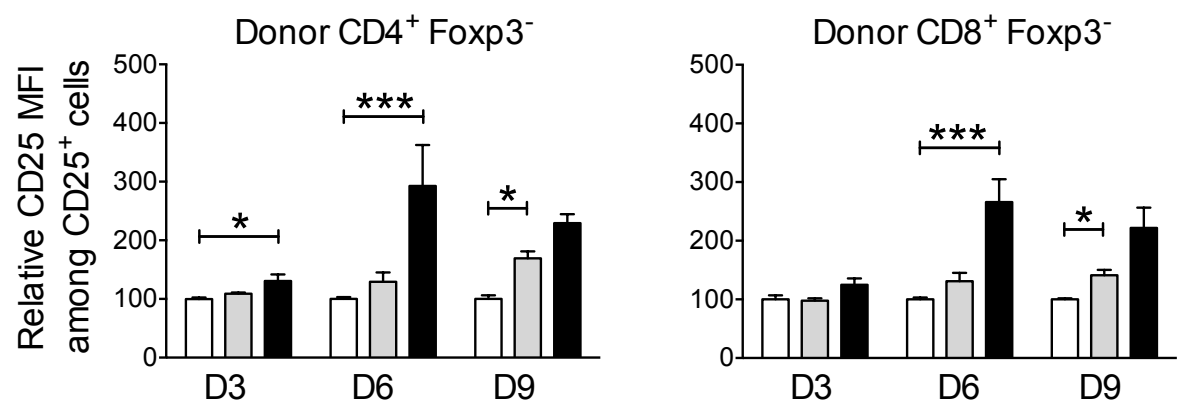


\section{Figure 7}

a

- PBS $(n=8)$

$\Delta \quad 25,000$ IU IL-2 ( $n=7)$

$\nabla 250,000$ IU IL-2 (n=8)
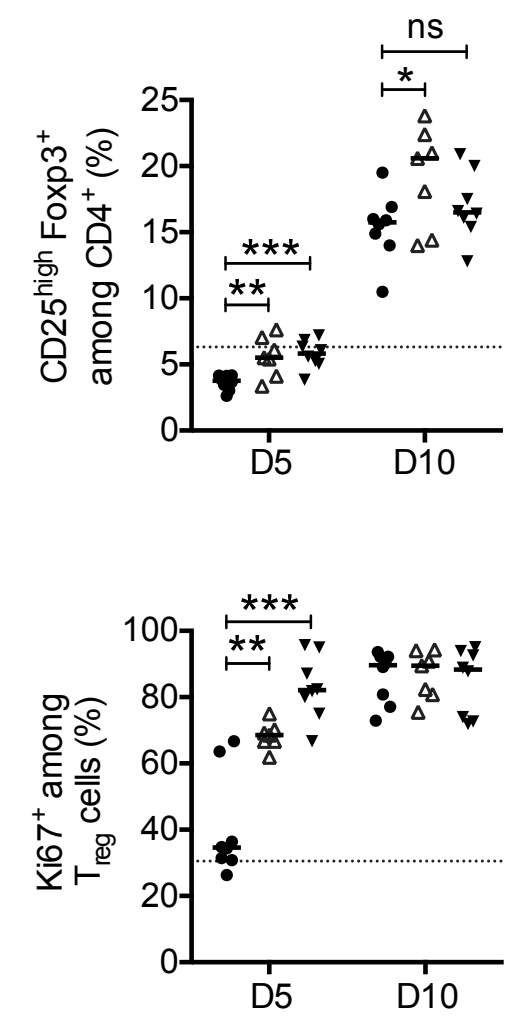

b

- PBS $(n=8)$

$\Delta \quad 25,000$ IU IL-2 ( $=7$ )

จ 250,000 IU IL-2 $(n=8)$

$\mathrm{CD}^{+}$Foxp $3^{-}$
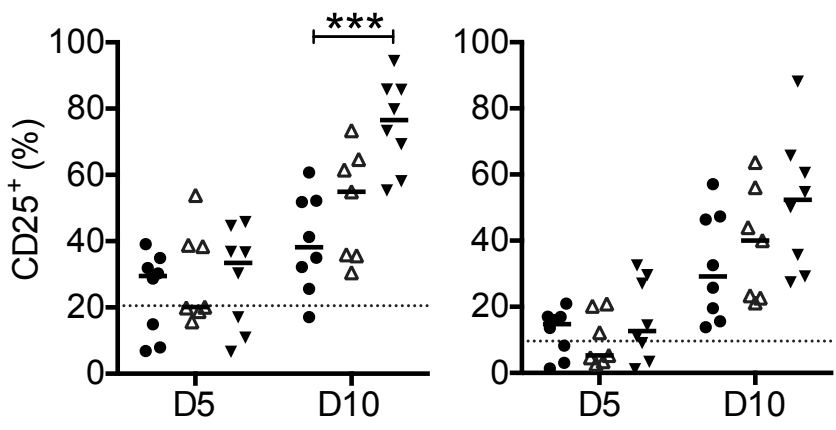

$\mathrm{CD}^{+}{ }^{+} \mathrm{Foxp}^{-}$

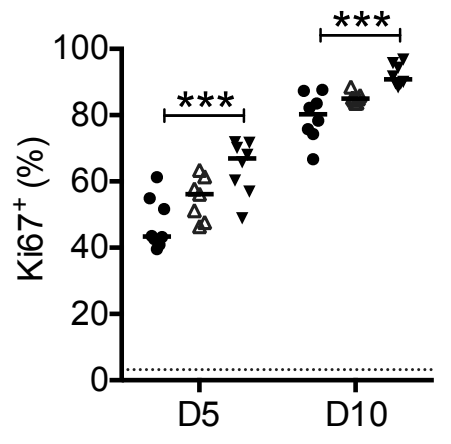

C

Day 10 post-graft

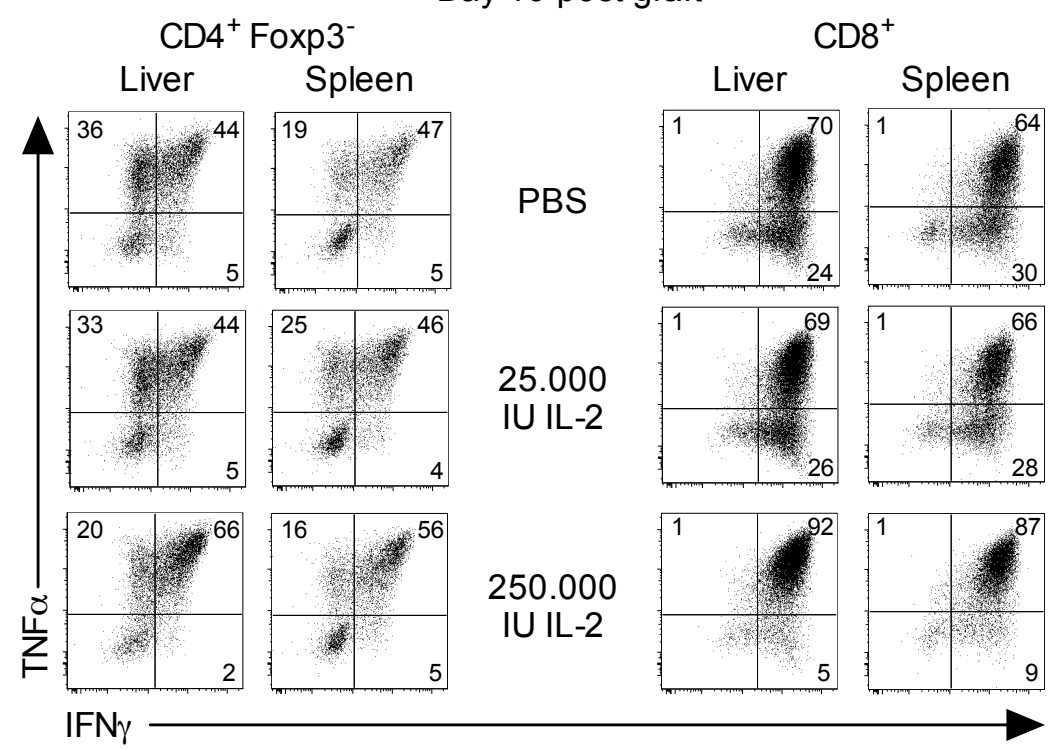

- PBS (n=4)

$\Delta \quad 25,000$ IU IL-2 (n=4)

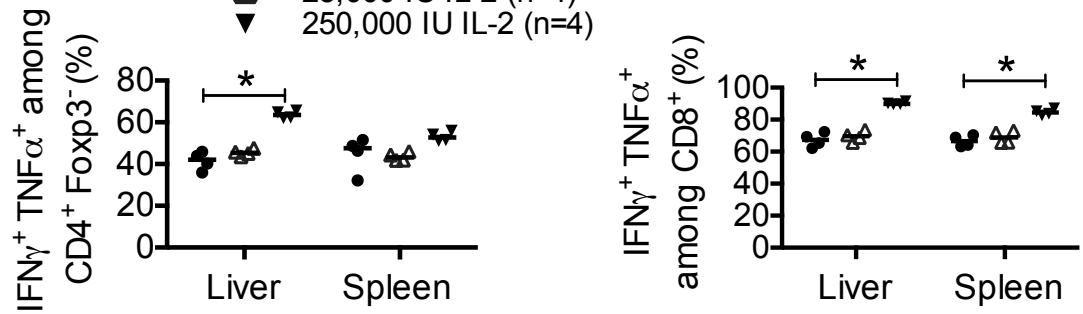


Figure 8

a

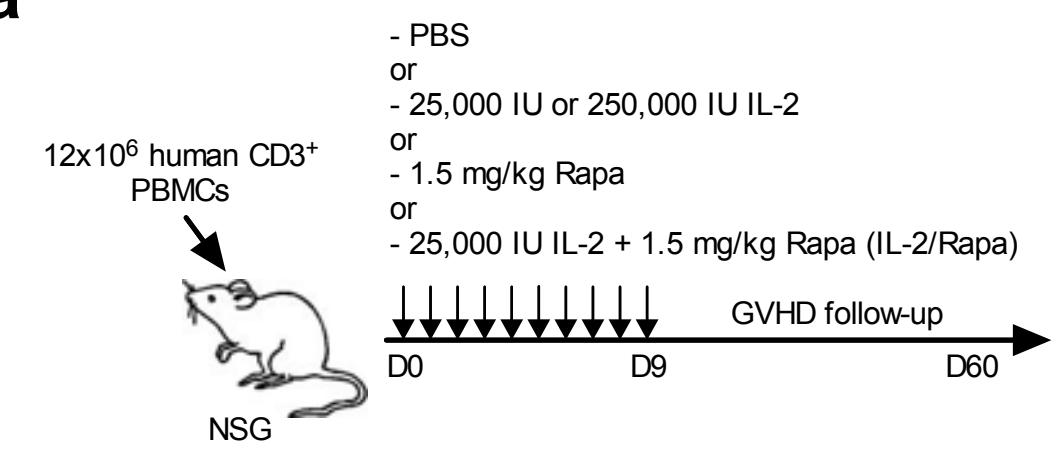

b

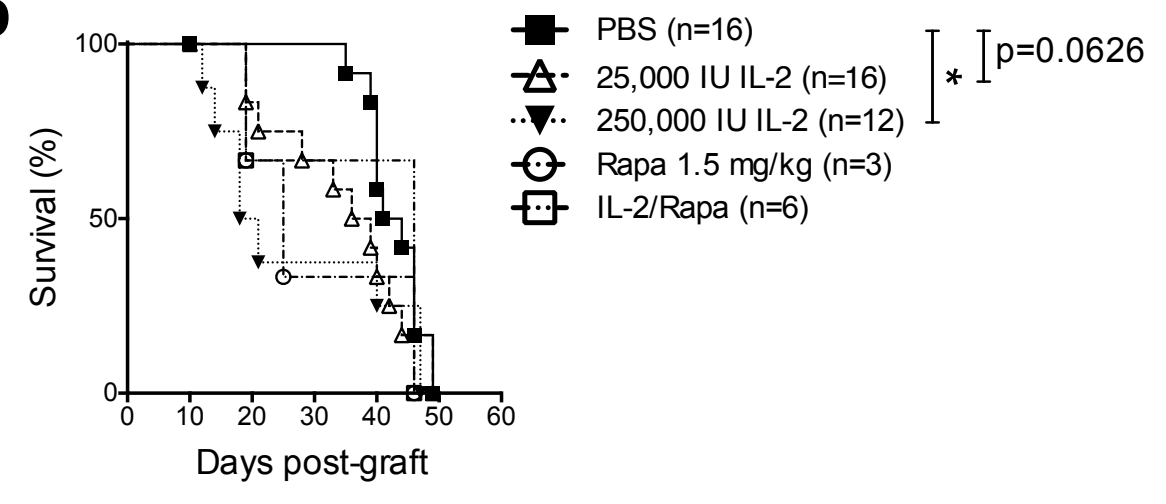




\section{Supplementary Figure 1}

a

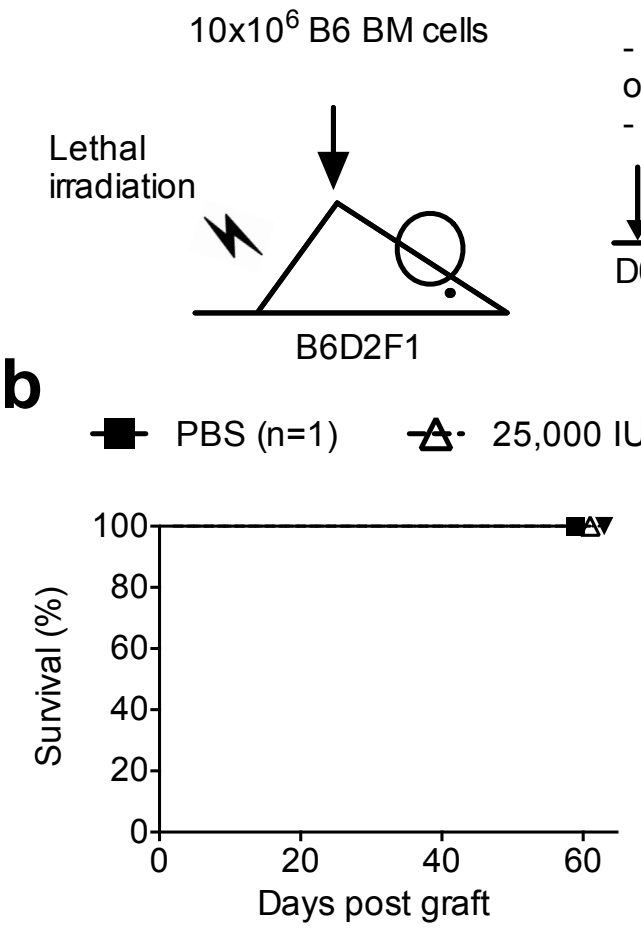

- PBS

or

- IL-2 (25,000 IU or 250,000 IU)

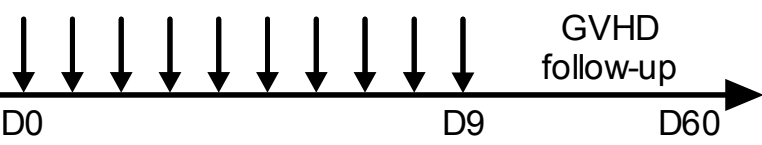

B6D2F1 


\section{Supplementary Figure 2}

a

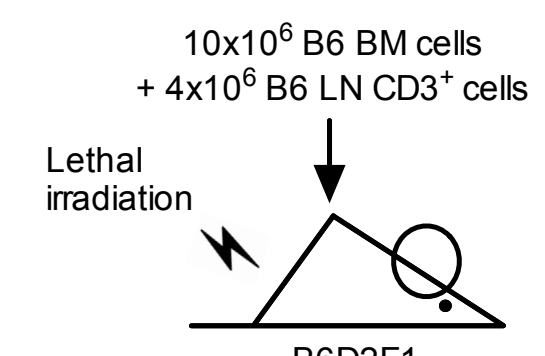

B6D2F1
- PBS

or

- IL-2 (25,000 IU)

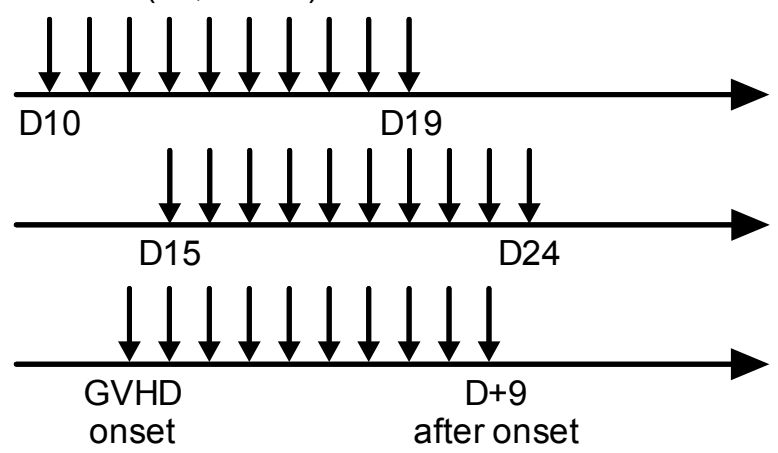

b

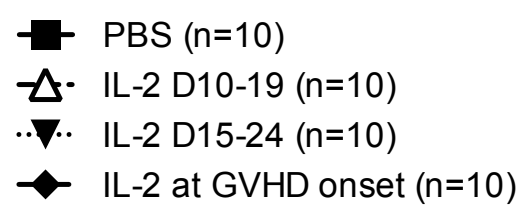

C
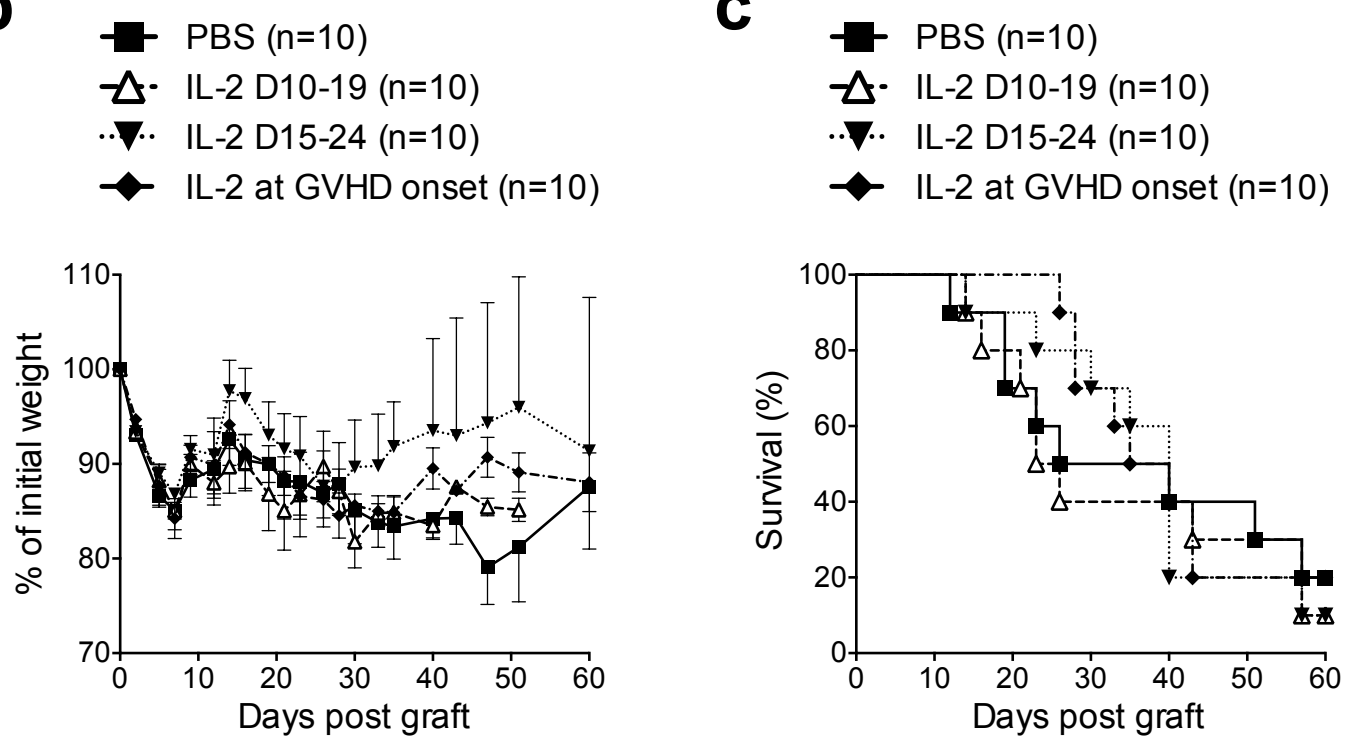

Supplementary figure 2. Curative low dose IL-2 treatment of recipient mice does not reduce GVHD incidence.

(a) GVHD experimental protocol: recipient B6D2F1 mice were lethally irradiated and grafted with $10.10^{6} \mathrm{~B} 6 \mathrm{BM}$ cells along with $4.10^{6}$ semiallogeneic $\mathrm{B} 6 \mathrm{LN} \mathrm{CD} 3^{+} \mathrm{T}$ cells. Recipient mice were then treated for 10 days with daily injections of PBS or $25,000 \mathrm{IU}$ IL-2 at different days post-graft: either from D10 to D19 (IL-2 D10-19), from D15 to D24 (IL-2 D15-24) or at GVHD onset (IL-2 at GVHD onset). (b) Kaplan-Meier survival curves and (c) weight curves. Graphs show cumulative data from 2 independent experiments with 5 mice per group. Errors bars are the S.E.M. of the mean value. 